\title{
Gephyrin and the regulation of synaptic strength and dynamics at glycinergic inhibitory synapses
}

\author{
Francisco J. Alvarez \\ Department of Physiology, Emory University, Atlanta, GA 30322-3110
}

Corresponding author:

Francisco J. Alvarez

Associate Professor

Department of Physiology

Emory University School of Medicine

Whitehead Research Building, Room 642

615 Michael Street

Atlanta, GA, 30322-3110

Email: Francisco.j.alvarez@emory.edu

Office phone: 404-727-5139

(C) 2016. This manuscript version is made available under the Elsevier user license http://www.elsevier.com/open-access/userlicense/1.0/ 
ABSTRACT: Glycinergic synapses predominate in brainstem and spinal cord where they modulate motor and sensory processing. Their postsynaptic mechanisms have been considered rather simple because they lack a large variety of glycine receptor isoforms and have relatively simple postsynaptic densities at the ultrastructural level. However, this simplicity is misleading being their postsynaptic regions regulated by a variety of complex mechanisms controlling the efficacy of synaptic inhibition. Early studies suggested that glycinergic inhibitory strength and dynamics depend largely on structural features rather than on molecular complexity. These include regulation of the number of postsynaptic glycine receptors, their localization and the amount of co-localized $\mathrm{GABA}_{\mathrm{A}}$ receptors and GABA-glycine co-transmission. These properties we now know are under the control of gephyrin. Gephyrin is the first postsynaptic scaffolding protein ever discovered and it was recently found to display a large degree of variation and regulation by splice variants, posttranslational modifications, intracellular trafficking and interactions with the underlying cytoskeleton. Many of these mechanisms are governed by converging excitatory activity and regulate gephyrin oligomerization and receptor binding, the architecture of the postsynaptic density (and by extension the whole synaptic complex), receptor retention and stability. These newly uncovered molecular mechanisms define the size and number of gephyrin postsynaptic regions and the numbers and proportions of glycine and $\mathrm{GABA}_{A}$ receptors contained within. All together, they control the emergence of glycinergic synapses of different strength and temporal properties to best match the excitatory drive received by each individual neuron or local dendritic compartment. 


\section{INTRODUCTION}

Glycinergic neurotransmission is most important in the inhibitory networks of the spinal cord, brainstem and retina, while GABAergic neurotransmission predominates in the forebrain. Glycinergic synapses operate through glycine-gated chloride channel-receptors (GlyR) with ion permeability similar to $\mathrm{GABA}_{A}$ receptors, but different conductance levels (Bormann et al., 1987; Smith et al., 1989). Importantly, glycinergic synaptic currents are usually of larger peak amplitudes and faster kinetics than those mediated by GABA $A_{A}$ receptors (Gonzalez-Forero and Alvarez, 2005; Jonas et al., 1998; Legendre, 2001; Takahashi et al., 1992), and perhaps better tuned to the synaptic integrative properties of spinal and brainstem neurons involved in motor control and sensory processing. Mutations affecting glycinergic neurotransmission are therefore tightly associated with motor problems and startle disease (Harvey et al., 2008; Schaefer et al., 2013), but they are also related to chronic pain (Lynch and Callister, 2006) and deficits in auditory processing (Wang et al., 2011).

The goal of this review is to highlight the central role of gephyrin (from the Greek $\gamma \varepsilon \varphi v \rho \alpha$ : "anchor" or "bridge"; Prior et al., 1992) in glycinergic synapse structure and function. Gephyrin is a protein of the postsynaptic density at inhibitory synapses that when first discovered it was proposed to serve as a GlyR anchoring protein (Pfeiffer et al., 1982; Triller et al., 1985), but thereafter it was found to encompass a large diversity of isoforms and posttranslational modifications that influence the size and density of postsynaptic receptor clusters and differentially modulate receptor recruitment and stability of not only GlyRs but also $\mathrm{GABA}_{A}$ receptors, thereby controlling important aspects of glycinergic synapse function like the amplitude and time course of the postsynaptic currents. In the initial sections of this review the functional significance of gephyrin postsynaptic clustering and its matching to convergent excitatory inputs will be considered. Later the molecular basis of gephyrin regulation and postsynaptic receptor recruitment and their modulation by synaptic activity will be discussed.

\section{BASIC ORGANIZATION OF GLYCINERGIC SYNAPSES}

Glycinergic synapses (Figure 1) lack the molecular complexity of $G_{A B A_{A}}$ synapses. Glycinergic synapses do not express the variety of presynaptic neurotransmitter synthesizing enzyme isoforms characteristic of GABAergic synapses and that finely modulate neurotransmitter synthesis and release. Glycinergic synapses neither display a large variety of postsynaptic receptor subunit compositions, similar to the $\mathrm{GABA}_{\mathrm{A}}$ receptor conferring different properties to GABAergic neurotransmission in different brain regions. At glycinergic synapses, glycine accumulates inside synaptic vesicles from a high cytosolic glycine concentration set predominantly by uptake from the extracellular space by plasma membrane glycine transporters, specifically the isoform 2 or GlyT2 (Gomeza et al., 2003; Latal et al., 2010; Rousseau et al., 2008). Lack of GlyT2 causes a dramatic reduction in glycinergic neurotransmission that is not compensated by metabolic glycine production or upregulation of GABA neurotransmission (Latal et al., 2010). Thus, GlyT2 knockout animals display a profound motor phenotype and die in the second postnatal week (Gomeza et al., 2003). Glycine is loaded into synaptic vesicles through the vesicular inhibitory aminoacid transporter (VIAAT) that is shared with GABA (Wojcik et al., 2006). Upon synaptic release, glycine interacts with postsynaptic GlyRs that, in the adult, are usually heteromeric pentamers composed by $\alpha 1$ and $\beta$ subunits with stoichiometry $3 \alpha: 2 \beta$ or $2 \alpha: 3 \beta$ (Dutertre et al., 2012; Legendre, 2001; Lynch, 2009). Glycine binds to the $\alpha$ subunit and double binding is necessary for GlyR openings 
that have characteristic short mean open times (Legendre, 2001; Takahashi et al., 1992) and result in the brief time courses of glycinergic synaptic currents. The genes for one type of $\beta$ subunit and $4 \alpha$ subunits have been identified and different subunit compositions display different kinetics and ligand affinities (Zhang et al., 2015). Further heterogeneity arises from splice variants, posttranslational modifications and the fact that some GlyRs are pentameric homomers of $\alpha$ subunits. However, GlyRs other than $\alpha 1 \beta$ heteromers have their expression restricted to development (i.e., $\alpha 2$ homomers) or limited distributions (i.e., $\alpha 2 \beta$ and $\alpha 3 \beta$ containing GlyRs are mostly found in retina, superficial spinal cord dorsal horn and cerebellum). More complete descriptions on the molecular biology, distribution and pharmacology of GlyRs can be found in other reviews (Dutertre et al., 2012; Legendre, 2001; Lynch, 2009). Compared to the variety of molecular organizations in the pre and postsynaptic elements of glutamatergic and GABAergic synapses, glycinergic synapses in the adult have fewer molecular variants that modulate neurotransmitter content presynaptically and fewer GlyR subunit combinations to influence ligand binding, channel kinetics and pharmacology, postsynaptically.

Glycinergic synapses nonetheless modify their function and synaptic strength by controlling, among others, three important variables: 1 ) the number of glycine postsynaptic receptors; 2 ) the localization of synapses in cell body, proximal or distal dendrites; 3) GABA co-transmission. All three features are regulated by gephyrin-dependent mechanisms, highlighting the importance of gephyrin as a central controller of glycinergic synapse structure and function. This review will focus on activity-dependent mechanisms of gephyrin regulation that modulate glycinergic synapse strength. More complete reviews on gephyrin molecular biology and its role in GABAergic synapses can be found elsewhere (Choii and Ko, 2015; Fritschy et al., 2008; Tretter et al., 2012; Tyagarajan and Fritschy, 2014; Zacchi et al., 2014).

\section{DIVERSITY OF GEPHYRIN CLUSTERING AND INHIBITORY GLYCINERGIC SYNAPSE ORGANIZATION}

Using gephyrin as a marker of the postsynaptic density of inhibitory synapses it was found that in the spinal cord in vivo, neurons display cell-type specific organizations of gephyrin clustering such that for most neurons, including $\alpha$ and $\gamma$-motoneurons, inhibitory synapses are distributed throughout the cell body and dendrites with structural variations in gephyrin postsynaptic densities that depend on synapse location (Alvarez et al., 1997). Proximal inhibitory synapses are opposed by 4 to 15 individual gephyrin rounded spots that are rather small $\left(<0.1-0.2 \mu \mathrm{m}^{2}\right.$ ) and organized in "rosettes" (Figure $\left.2 \mathrm{~A}\right)$. The lower boundaries of their size distribution was initially ambiguous because the diffraction limit in resolving power of wide-field and confocal microscopy, but using superresolution techniques it was recently estimated that small clusters in spinal cord neurons average around $0.06 \mathrm{\mu m}^{2}$ in size (Specht et al., 2013). In contrast, gephyrin patches coalesce in the distal dendrites where they form fewer clusters, but of larger size (from 0.2 to more than $1 \mu \mathrm{m}^{2}$ ) and variable morphologies. This sets a somatodendritic gradient in which proximal inhibitory synapses are opposed by several small, circular and independent gephyrin clusters, while synapses on the distal dendrites are opposed by fewer more pleomorphic larger patches. A similar organization was observed in the Mauthner cell of the teleost fish brainstem (Triller et al., 1990). One exception to this somatodendritic gradient in the mammalian spinal cord is a class of spinal interneuron that provides feedback inhibition to motoneurons and is known as the Renshaw cell (Eccles et al., 1954; Renshaw, 1946). Renshaw cells lack gephyrin and inhibitory synapses in their distal dendrites, but their cell body and proximal dendrites are covered by a high density of inhibitory synapses ( $>90 \%$ of the total synaptic coverage on the cell bodies, Alvarez F.J., unpublished results) with 
extraordinarily large postsynaptic gephyrin patches, some larger than $3.5 \mu \mathrm{m}^{2}$ (Alvarez et al., 1997; Geiman et al., 2000)(Figure 2A). In all cases the glycinergic nature of gephyrin-labeled inhibitory synapses was confirmed by co-labeling against GlyR subunits and the distribution of postsynaptic GlyRs was co-extensive with the gephyrin clustering area. Gephyrin is also an organizer of postsynaptic densities in forebrain inhibitory synapses, but in this case the synapses are purely GABAergic, lacking GlyRs. Although GABAergic synapses also display considerable heterogeneity depending on cell type and $\mathrm{GABA}_{\mathrm{A}}$ receptor subunit composition, they however do not form gephyrin clusters of the largest sizes and do not display systematic proximo-distal gradients in gephyrin cluster size and morphologies along dendrites (Sassoe-Pognetto et al., 2000).

Since gephyrin lies beneath the full extent of inhibitory postsynaptic densities (Triller et al., 1985) and there is a perfect match between the presynaptic active zone and postsynaptic densities, gephyrin clustering is in fact a mirror image of the presynaptic active zones. Therefore the size and shape of gephyrin clusters reveal structural variations on the organization of the active zone, postsynaptic density and intervening synaptic cleft at inhibitory synapses (Figure $2 \mathrm{C}$ ). At one extreme presynaptic inhibitory boutons form multiple structurally independent active zones or release sites each opposed to a small gephyrin-containing postsynaptic density. At the other, the synaptic bouton establishes a single and large active zone opposed by a similarly large gephyrin containing postsynaptic density. Over the surface of individual neurons the distribution of gephyrin clusters therefore correspond with either a "cheetah"-like or "jaguar"-like spot marking (Figure 2B). As explained below, similar to their feline equivalents they might correspond with either fast synapses of lesser strength or more robust and slower synapses (Figure 2B). The postsynaptic element seems to define these properties because synaptic varicosities from single glycinergic axons are associated with different postsynaptic gephyrin architectures depending on whether they contact proximal or distal dendrites (Alvarez et al., 1997).

\section{THE POSTSYNAPTIC STRUCTURE OF GLYCINERGIC SYNAPSES MATCHES THE EXCITATORY SYNAPTIC ACTIVITY OF THE DIFFERENT LOCAL NEURONAL COMPARTMENTS}

The structure of inhibitory synapses is adapted to the different strengths and dynamics of the excitatory postsynaptic potentials (EPSPs) they are designed to counter at either distal dendrites, proximal somatodendritic regions, or in different cell types. Renshaw cells are rather unique in that they receive excitation from intraspinal synaptic collaterals of motor axons (Eccles et al., 1954). These synapses are characterized by high quantal content and high probability of release and elicit large and long mixed nicotinic/NMDA postsynaptic currents that reliably evoke bursts of action potentials (Lamotte d'Incamps and Ascher, 2008; Mentis et al., 2005; Moore et al., 2015; Ross et al., 1976; Van Keulen, 1981). Thus inhibitory control of this excitatory input is expected to necessitate high amplitude and long lasting inhibitory synaptic currents in the proximal dendrites and cell bodies of Renshaw cells (Gonzalez-Forero and Alvarez, 2005). Similarly, EPSPs on distal dendrites are of higher amplitude than on proximal regions in many neurons (Magee, 2000). This is in part because passive electrical properties (membrane resistance and capacitance) in increasingly smaller dendritic compartments magnify the membrane potential change to similar synaptic currents, but importantly, excitatory synaptic conductances also increase with distance to the cell body. In addition, most dendrites are endowed with active properties that depend on dendrite voltage-gated $\mathrm{Ca}^{2+}$ and/or $\mathrm{Na}^{+}$channels. These further modulate temporal and spatial summation of dendritic EPSPs and generally amplify these signals compensating for dendritic 
electronic filtering as they travel towards the cell body and axon initial segment. Thus, by increasing distal dendrite EPSP amplitudes and adjusting their time-course at the point of origin, the amplitudes and time courses of EPSPs reaching the cell body become independent of where they originate on the dendrite. This normalizes the relative weights of synapses from different locations during synaptic integration at the cell body. It also predicts a progressive increase in local EPSP amplitudes in dendritic locations further from the cell body (see review by Magee in 2000 for a more complete discussion). Accordingly, EPSPs in both Mauthner cells (Korn et al., 1993) and motoneurons (lansek and Redman, 1973; Jack et al., 1981) have been shown to increase in magnitude in distal dendrites, precisely in the same compartments where inhibitory synapses with larger gephyrin clusters reside (Alvarez et al., 1997; Triller et al., 1990).

Moreover, motoneuron dendrites have strong active properties that manifest as persistent inward currents (PICs), designed to further amplify dendritic EPSPs as they propagate towards the cell body (Binder, 2002; Heckman et al., 2008). PICs, particularly those generated by Cav1.2 and Cav1.3 calcium channels (L-type $\mathrm{Ca}^{2+}$ currents) have slow de-activation kinetics, show strong facilitation and can generate bistable behaviors that increase firing responses to weak inputs (Hounsgaard et al., 1988) contributing to both synaptic amplification and neuron excitability (Binder, 2002; Heckman et al., 2008). These mechanisms could eventually saturate synaptic integration unless turned off by hyperpolarization through local inhibitory synapses. Thus, large (and perhaps slower) inhibitory synapses on dendrites are perhaps best designed to control not only larger EPSPs, but also dendrite active conductances with characteristic slow de-activation kinetics and history-dependent facilitation.

\section{GEPHYRIN CLUSTER ARCHITECTURES AND POSTSYNAPTIC INHIBITORY RECEPTOR ACCUMULATIONS DEVELOP POSTNATALLY AND ARE MODULATED BY EXCITATORY DRIVE}

The large diversity of gephyrin clusters visible in adult spinal neurons is not present in embryos and neonates, and can hardly be replicated in vitro (van Zundert et al., 2004). Gephyrin clusters on spinal cord neurons in situ are consistently of larger size and gephyrin content than on primary cultures of spinal neurons in vitro (Specht et al., 2013). Mature large gephyrin clusters emerge on Renshaw cells during the first two postnatal weeks, in vivo (Geiman et al., 2000) and are regulated by the level of excitatory input the neuron receives during this period (Gonzalez-Forero et al., 2005). Similarly, "rosette" organizations in the proximal dendrites and cell bodies of most spinal neurons also develop postnatally by addition of new independent active zone-gephyrin clusters (Alvarez F.J., unpublished observation). The recent development of EGFP-gephyrin mice allowed more detailed analysis of gephyrin cluster maturation in organotypic cultures of brain slices (Vlachos et al., 2013). In this preparation gephyrin cluster size increased over a 4-week period and photo-recovery after bleaching (FRAP) experiments demonstrated a significant reduction in gephyrin turnover rates in the larger and more mature clusters compared to the more immature smaller clusters. Therefore during postnatal development gephyrin clusters undergo significant changes in structure, increasing their size and number and also stabilizing gephyrin inside the postsynaptic density. This period of gephyrin cluster maturation in spinal cord synapses coincides with the upregulation of voltage-gated $\mathrm{Ca}^{2+}$ channel subunit expression in motoneurons and an increased sensitivity of the motor output to L-type $\mathrm{Ca}^{2+}$ channel blockers (Jiang et al., 1999), as well as with increases in $\mathrm{Na}^{+}$PICs (Quinlan et al., 2011). Gephyrin 
maturation on dendrites therefore correlates with increases in excitatory synaptic drive and active dendritic conductances, particularly calcium channels.

However, in comparison to other synapses in vitro, gephyrin clusters in spinal neurons, many of which are mixed GABA/glycine synapses, did not show large changes in size or gephyrin content resulting from homeostatic synaptic plasticity after a 48 hour tetrodotoxin activity block in culture (Specht et al., 2013). This activity block reduced however $\mathrm{GABA}_{A}$ receptor content in gephyrin postsynaptic aggregates, but not GlyR numbers. Therefore, long-term changes in gephyrin and/or GlyR content in response to decreased activity might be slower (and perhaps more permanent) compared to $\mathrm{GABA}_{\mathrm{A}}$ receptors, suggesting higher stabilization of gephyrin-GlyR postsynaptic complexes compared to gephyrin-GABA receptors. Consistent with this conclusion single particle tracking experiments that directly compared the mobility of $G A B A_{A}$ receptors and GlyRs on cultured spinal neurons confirmed larger confinement of GlyRs to synapses, while $G_{A B A}$ receptors displayed higher mobility across the synaptic area and tended to escape more easily than GlyRs from synaptic sites (Levi et al., 2008). Increased activity in these same spinal neuronal cultures induced by short term (maximum 2 hours) block of GlyRs or GABA receptors, or activating NMDA receptors all decreased GlyR synaptic mobility and increased synaptic GlyR number and glycinergic miniature postsynaptic inhibitory currents (mIPSCs) amplitudes through a mechanism that required calcium and the activation of L-type voltage $\mathrm{Ca}^{2+}$ channels (Levi et al., 2008). These manipulations did not change $\mathrm{GABA}_{\mathrm{A}}$ receptors in agreement with previous in vivo experiments showing that altering motor axon excitatory input to Renshaw cells during the first two weeks of postnatal development had large effects on gephyrin clusters and glycinergic mIPSCs, but not in GABAergic mIPSCs elicited at the same mixed inhibitory synapses (Gonzalez-Forero et al., 2005). Gephyrin cluster size was however unchanged during acute pharmacological manipulations of activity in vitro (Levi et al., 2008) in contrast to the significant changes in gephyrin cluster areas after long term ( 2 weeks) alteration of excitatory drive during in vivo development (Gonzalez-Forero et al., 2005). Taken together, the results of these studies suggest that recruitment of postsynaptic GlyRs by excitatory activity can be rapidly accomplished by increasing GlyR content at existing gephyrin clusters or more slowly (and perhaps more permanently) by increasing gephyrin cluster size. The first mechanism implies that gephyrin molecules must exceed the number of GlyRs present to allow for rapid changes in GlyR density over gephyrin postsynaptic scaffolds. It is conceivable that there is an upper limit to increases in GlyR density after which gephyrin clusters need to grow to add more GlyRs. Both mechanisms resulted in little change in the number of co-localized $G_{A B A}$ receptors. Nevertheless, plasticity of gephyrin cluster sizes in response to different levels of excitation, has been now confirmed in "pure" GABAergic synapses of the hippocampus (Flores et al., 2015), and recruitment of $\mathrm{GABA}_{A}$ receptors at synaptic sites on hippocampal neurons in vivo in response to epileptic seizures has long been known (Nusser et al., 1998). Excitatorydriven decreases in $\mathrm{GABA}_{A}$ receptor content can also occur in hippocampal neurons under certain excitation paradigms. In this case $\mathrm{GABA}_{A}$ receptors increase their mobility and dispersion from the postsynaptic density also independently of changes in gephyrin clustering (Niwa et al., 2012). It thus appears that gephyrin clustering is regulated by excitatory synaptic activity in ways that differ depending on the types of inhibitory synapses and brain regions. To conclude, recruitment and stabilization of $G_{A B A_{A}}$ receptors might differ between spinal cord inhibitory synapses co-expressing GlyRs and forebrain GABA "only" synapses; moreover the control of GABA $A_{A}$ receptor numbers seems not as tightly co-related to gephyrin clustering as is the recruitment and retention of GlyRs. 


\section{FUNCTIONAL CORRELATES OF GEPHYRIN AND GLYCINE RECEPTOR CLUSTERS OF DIFFERENT SIZES}

The above considerations lead to the hypothesis that larger gephyrin clusters develop in specific neurons and cell compartments in response to local excitation and to generate inhibitory synaptic potentials (IPSPs) of larger amplitude (due to more postsynaptic receptors) and slower time course (resulting from lower clearance of glycine from larger synaptic clefts). However these functional correlates are not as straightforward as they may appear because they assume a certain level of saturation of postsynaptic GlyRs such that increments in amplitude are mostly the result of additional GlyRs and not variations in the duration and concentration of glycine in the synaptic cleft. The functional significance of gephyrin clustering was directly tested for the first time in whole cell voltage clamp recordings from bushy cells of the anteroventral cochlear nucleus (AVCN) in the brainstem (Lim et al., 1999). This neuron was advantageous because it lacks well-formed dendrites and therefore permits accurate measurements of quantal (responses to glycine released from a single vesicle) mIPSCs without alterations due to filtering through the dendrites passive or active properties (Isaacson and Walmsley, 1995). Fortunately, AVCN bushy neurons included some cells with inhibitory synapses with mostly small gephyrin clusters and others with many inhibitory synapses containing large gephyrin clusters. In a sample of AVCN cells in which mIPSCs and gephyrin cluster size distributions were measured in the same cells, the average peak amplitude of quantal synaptic currents (mIPSCs) was significantly correlated with the average size of gephyrin clusters, although there was also significant variability (Lim et al., 1999).

In contrast, other studies concluded that glycinergic synapses operate mainly in unsaturated conditions and proposed alternative mechanisms to explain the variability of quantal synaptic currents. Variant glycinergic quantal amplitudes in the inhibitory synapses over Mauthner cells were proposed to arise mainly due to the stochastic nature of channel openings and glycine-GlyR interactions which result in opening variable proportions of the full ensemble of postsynaptic GlyRs in response to released glycine (Faber et al., 1992). In a follow up modelling study it was shown that even assuming an excess of neurotransmitter release to obtain $100 \%$ GlyR occupancy, the low probability channel gating kinetics predicted that only $80 \%$ of glycine-bound-GlyRs would open simultaneously (Kruk et al., 1997). This probability decreases further with increased numbers of postsynaptic GlyRs. Receptor saturation was also affected by the size of the postsynaptic receptor cluster and counterintuitively GlyR clusters of smaller diameter saturated less because the rapid diffusion kinetics of glycine from the cleft prevented complete binding coverage of postsynaptic GlyRs by glycine. These factors create complex relations between quantal mIPSC amplitudes, the geometry of postsynaptic gephyrin clusters and the number of postsynaptic GlyRs. Lack of GlyR saturation at glycinergic synapses was confirmed in experiments using zinc, which allosterically increases GlyR affinity for glycine and potentiates agonist channel gating. Zinc increased mIPSC amplitudes in Mauthner cells despite the fact that the estimated glycine concentration in the cleft was $1 \mathrm{mM}$ and therefore sufficient for full occupancy of all available GlyRs (Suwa et al., 2001). The authors argued that GlyR activation kinetics are slower than glycine diffusion and therefore, even in the case of large concentrations of neurotransmitter, postsynaptic receptors display variable levels of saturation resulting in mIPSC amplitude fluctuations in normal conditions and increased mIPSC amplitudes in the presence of zinc.

Can mIPSC amplitude in unsaturated synapses correlate tightly with the number of postsynaptic receptors and postsynaptic cluster sizes? Although all Mauthner cells studied in zebrafish larvae display similar distributions of gephyrin-GlyR cluster sizes on their cell surface and the variation in cluster sizes is not as extreme as reported over adult mammalian spinal neurons or AVCN cells (Alvarez et al., 1997; Lim 
et al., 1999), mIPSC amplitudes sizes did co-vary closely with GlyR cluster sizes (Suwa et al., 2001). This suggests that even in non-saturating conditions and within a narrow distribution of GlyR cluster sizes, mIPSC amplitude closely parallels postsynaptic GlyR-gephyrin cluster size. This conclusion is strengthened by comparing the mIPSC amplitude distributions in Mauthner cells of adult goldfish to zebrafish larvae which display GlyR clusters that differ up to 10 times in size (Korn et al., 1982; Suwa et al., 2001; Triller et al., 1990). One further study examined GlyR activation on hypoglossal motoneurons after brief $(1 \mathrm{~ms})$ pulses of $1 \mathrm{mM}$ glycine that mimicked synaptic release and concluded that variance in glycine-GlyR interactions accounts for $10-25 \%$ of amplitude variability, and proposed that the main source of change in quantal amplitude at glycinergic synapses should arise from changes in the number of postsynaptic receptors, as will occur due to differences in gephyrin clustering (Singer and Berger, 1999). Not surprisingly, the peak amplitude of the glycinergic component in Renshaw cells mIPSCs rapidly increased through postnatal development by $>200 \%$ (Gonzalez-Forero and Alvarez, 2005), in parallel with the developmental enlargement of gephyrin clusters (Geiman et al., 2000). Moreover, modulation of gephyrin clustering by manipulation of the excitatory input was correlated with changes in peak glycinergic mIPSCs in the same direction (Gonzalez-Forero et al., 2005). The above studies therefore demonstrate that gephyrin cluster size is tightly correlated with the peak amplitude of quantal events at glycinergic synapses although the synapses likely operate in unsaturated conditions allowing for several biophysical properties of the synapse (glycine diffusion, GlyR affinity and channel gating kinetics) to introduce some variability in this relationship.

Therefore larger gephyrin patches contain more postsynaptic GlyRs that elicit larger quantal currents. A recent analysis using fluorescence decay of mRFP-gephyrin directly quantified gephyrin content in cultured spinal neurons and found a close correlation between gephyrin and GlyR enrichment at individual synaptic sites (Specht et al., 2013). Similarly, a correlation was found between the sizes of postsynaptic densities and receptor content at GABAergic synapses using direct counting of immunolabeled $\mathrm{GABA}_{A}$ receptor particles in freeze-fractured replicas of inhibitory synapses on CA1 pyramidal cells (Kasugai et al., 2010). A positive correlation was found despite the fact that the range of sizes of these GABAergic synapses was much smaller than in the glycinergic synapses described above. Finally, GABA $A$ receptor numbers were also directly correlated with GABAergic mIPSCs in cerebellar stellate cells with unusually large variability in GABA quantal inhibitory current amplitudes (Nusser et al., 1997), that is similar to AVCN and spinal cord glycinergic synapses. In conclusion, the size of the postsynaptic density defined by the gephyrin cluster is directly correlated with postsynaptic receptor content and the amplitude of the postsynaptic currents in both glycinergic and GABAergic synapses. However, glycinergic synapses normally display a larger range of gephyrin cluster sizes and quantal amplitudes compared to GABAergic "only" synapses. In addition some variance in quantal amplitudes seems related to differences in receptor saturation. This variability is generally larger at the usually smaller GABAergic "only" synapses which also incorporate postsynaptic $\mathrm{GABA}_{\mathrm{A}}$ receptors with higher diversity of isoforms, affinities and kinetics (Barberis et al., 2004; Hajos et al., 2000; Mody and Pearce, 2004).

It has been more difficult to establish the influence of gephyrin cluster size on glycinergic inhibitory postsynaptic potentials (IPSPs) or inhibitory postsynaptic currents (IPSCs) time courses. In contrast to GABAergic and glutamatergic synapses, GlyRs desensitize slowly and glycine uptake does not significantly affect IPSP decays. Therefore, it is generally believed that the main factors controlling the decay of glycinergic synaptic currents are glycine clearance from the synaptic cleft through diffusion 
(Titmus et al., 1996) and the different de-activation rates of GlyRs of different subunit compositions; $\alpha 2$ based GlyRs have longer open times and undergo more complete desensitization than $\alpha 1$ containing GlyRs (Takahashi et al., 1992; Zhang et al., 2015). Thus, glycinergic IPSC decay times become faster during development as immature $\alpha 2$-containing GlyRs are replaced by mature $\alpha 1$-containing GlyRs, as previously reviewed (Aguayo et al., 2004; Legendre, 2001; Lynch, 2009). On the other hand, larger synaptic clefts and postsynaptic receptor fields should slow down diffusion, permit several cycles of glycine binding and unbinding and lengthen the postsynaptic current. However, no clear evidence of a lengthening in decay times was noted when comparing AVCN bushy cells or spinal neurons with large or small postsynaptic gephyrin clusters (Gonzalez-Forero and Alvarez, 2005; Lim et al., 1999; Oleskevich et al., 1999). Interestingly, glycine diffusion models suggest that the morphological parameter better corelated with slowing down IPSP kinetics is the total area of apposition between the presynaptic bouton and the postsynaptic neuron surface (Kruk et al., 1997), not the size of the GlyR-containing postsynaptic patch or the synaptic complex itself (defined as the presynaptic active zone and matching opposing postsynaptic density). This could explain why glycinergic mIPSC decays are similar in synaptic boutons with multiple small gephyrin patches and synaptic boutons opposed to one or few larger gephyrin patches, since both have similar lengths of apposition with the postsynaptic neuron (Alvarez et al., 1997)(see Figure 2C). Incorporation of slower $\mathrm{GABA}_{A}$ receptors in larger gephyrin patches and glycineGABA co-transmission introduces a more significant slowing of the time course of the inhibitory synaptic current and the IPSP (see below).

Because the size and shape of the presynaptic active zone is well matched with the postsynaptic density, differing gephyrin cluster structures also predict differences in release mechanisms at the active zone. Although these have not been studied in detail specifically at glycinergic synapses, analyses performed in GABAergic and glutamatergic synapses suggest that active zone sizes determine the number of vesicle docking sites and the number of voltage-gated channels, both affecting release probability, multivesicular release, the size of the ready releasable vesicle pool and short-term synaptic plasticity (Holderith et al., 2012; Pulido et al., 2015; Schikorski and Stevens, 1997; Sheng et al., 2012). It would be interesting to have similar analyses performed at glycinergic synapses displaying much larger ranges in active zone size than the glutamatergic and GABAergic synapses studied up to date.

Finally, the exact functional differences between glycinergic synapses that establish one larger active zone or several smaller ones are not fully clear. It is however noteworthy that the structure of very large excitatory synapses with hundreds of small active zones, like the neuromuscular junction (NMJ) and the calyx of Held over AVCN neurons, mature postnatally (Cano et al., 2013; Taschenberger et al., 2002), similar to gephyrin clustering on spinal neurons. The compound effects of adding small independent active zones through development in the NMJ and the calyx of Held are increases in the overall bouton (all active zones together) probability of release, quantal content and the size of the releasable vesicle pool while reducing at individual active zones mutivesicular release and allowing faster clearance, both diminishing postsynaptic receptor saturation and desensitization. Together these properties increase reliability and speed of neurotransmission during high-frequency firing (Cano et al., 2013; Taschenberger et al., 2002). It is tempting to speculate that glycinergic inhibitory boutons with many independent small active zones are designed for speed reliability, compared to inhibitory synapses that develop just one large active zone and postsynaptic area, which may be better designed for enlarging postsynaptic current amplitude and lengthening its time course (by also adding slower $\mathrm{GABA}_{A}$ receptors, see below). 


\section{MOLECULAR MECHANISMS OF GEPHYRIN AND GLYCINE RECEPTOR ACCUMULATION IN THE POSTSYNAPTIC MEMBRANE}

Gephyrin binds with high affinity to the GlyR $\beta$ subunit (Meyer et al., 1995), and this strong binding led to its discovery as a $93 \mathrm{kDa}$ cytoplasmic protein that tightly co-purifies with GlyRs in stoichiometric amounts (Pfeiffer et al., 1982). Gephyrin knock down in either cultured neurons or whole animals demonstrated that gephyrin-GlyR binding is necessary for the postsynaptic accumulation of GlyRs (Feng et al., 1998; Kirsch et al., 1993). In addition, GlyR activation and membrane depolarization in embryonic spinal neurons in primary cultures drives gephyrin to the postsynaptic membrane through a mechanism dependent on the opening of voltage-gated $\mathrm{Ca}^{2+}$ channels (Kirsch and Betz, 1998; Levi et al., 1998). On the other hand, gephyrin oligomerization below the postsynaptic membrane and gephyrin interaction with the $\beta$ subunit binding motif are both necessary for confining GlyRs to postsynaptic regions and the stabilization of gephyrin clusters below the synaptic membrane (Calamai et al., 2009; Meier et al., 2001). Therefore, the current model of gephyrin clustering during the formation of glycinergic synapses suggests reciprocal interactions between GlyRs and gephyrin. First, GlyRs recruit gephyrin to certain locations below membrane regions where GlyRs are activated (at least during the developmental stages when GlyR openings depolarize neurons); thereafter gephyrin clusters enlarge and recruit further GlyRs to the site. GlyR accumulation in turn strengthens the submembrane gephyrin attachment and stability (note that this sequence of events is not necessarily the same at GABAergic synapses, see below).

Single particle tracking shows that GlyR accumulation at postsynaptic sites occurs through a trapping mechanism that sequesters into the postsynaptic gephyrin scaffold freely diffusing extrasynaptic GlyRs that are sometimes bound to non-oligomerized gephyrin (Dahan et al., 2003; Ehrensperger et al., 2007; Maas et al., 2006). This model suggests that GlyR-gephyrin complexes might be pre-formed and trafficked together before membrane insertion, and indeed, gephyrin was found to undergo intracellular co-transport with GlyRs over microtubules (Hanus et al., 2004; Maas et al., 2006). Interestingly, microtubule dependent GlyR-gephyrin co-transport is accelerated in neuronal cultures in response to $\mathrm{KCl}$ depolarization (Maas et al., 2006). A similar mechanism might contribute to the delivery of gephyrin to dendritic synapses after GlyR activation, as it was determined that GlyR antagonism alters microtubule posttranslational modifications and reduces dendritic anterograde delivery of GlyRgephyrin complexes via kinesin motors (Maas et al., 2009). These mechanisms are critical during initial formation and early maturation of glycinergic synapses. Interfering with microtubule stability decreased the amplitude and frequency of glycinergic mIPSCs and the size of synaptic gephyrin clusters in primary cultures of immature, but not mature, spinal neurons (van Zundert et al., 2004). Interestingly, many of these same synapses co-release GABA, but in contrast to GlyRs, $\mathrm{GABA}_{\mathrm{A}}$ receptor clusters and GABAergic mIPSCs were unaffected (van Zundert et al., 2004; van Zundert et al., 2002). This suggests that microtubule-gephyrin interactions are not necessary for $\mathrm{GABA}_{\mathrm{A}}$ receptor transport or co-accumulation with GlyRs at inhibitory synapses on spinal neurons. Thus, at glycinergic synapses, membrane depolarization regulates intracellular trafficking of gephyrin-GlyRs, the formation and enlargement of membrane gepyhrin clusters and the buildup of postsynaptic GlyRs through additions of freely diffusing extrasynaptic GlyR-gephyrin complexes to postsynaptic gephyrin scaffolds (Figure 3). The result are postsynaptic regions containing clustered gephyrin at densities between 5,000 to 10,000 molecules/ $\mathrm{\mu m}^{2}$ and 1:1 stoichiometry with GlyR binding sites (Specht et al., 2013). This implies that smaller gephyrin clusters contain from a few hundred to over 1,000 gephyrin molecules, while the larger clusters might contain tens of thousands of gephyrin molecules. 
A possible signaling pathway linking membrane depolarization, $\mathrm{Ca}^{2+}$ entry and gephyrin-GlyR clustering involves $\mathrm{Ca}^{2+} /$ calmodulin-dependent protein kinase II (CaMKII). In response to excitatory input CaMKII translocates to the postsynaptic density of inhibitory synapses and phosphorylates gephyrin increasing both gephyrin cluster size and density (Flores et al., 2015; Marsden et al., 2010). Moreover, the dependence on GlyR activation for the initial formation and stabilization of postsynaptic gephyrin-GlyR clusters was recently confirmed in vivo in zebrafish larvae Mauthner cells and was found to be also mediated by CaMKII activity (Yamanaka et al., 2013). CaMKII also modulates gephyrin and GlyR clustering in response to non-synaptic signals, like those from integrins; $\beta 3$ integrin increases gephyrin clustering and GlyR confinement to synapses and $\beta 1$ decreases both (Charrier et al., 2010). $\beta 3$ and $\beta 1$ integrins respectively activate and inhibit CaMKII function and can respond to a variety of signals, many of which also adjust synaptic strength at excitatory synapses (McGeachie et al., 2011). Thus, CaMKIImediated gephyrin phosphorylation integrates membrane depolarization and multiple other signals related to excitatory synapse activity to modulate gephyrin cluster size and GlyR recruitment (Figure 3). As will be reviewed below, other $\mathrm{Ca}^{2+}$ dependent mechanisms are involved in gephyrin degradation and declustering and therefore the direction of the gephyrin clustering change is probably related to temporal properties of the $\mathrm{Ca}^{2+}$ signals and their compartmentalization, affecting the type of intracellular signaling pathways activated.

\section{THE ROLE OF THE SUBSYNAPTIC CYTOSKELETON}

The actions of excitatory synaptic activity on both cluster sizes and numbers permits speculation about possible mechanisms that generate either a few larger postsynaptic clusters or several smaller independent ones opposite to individual synaptic boutons. How this might be regulated is presently unknown, but one possible mediator is the submembrane actin cytoskeleton. Actin dynamics likely regulate the architecture of the inhibitory synaptic region similarly to how it influences the structure and function of excitatory synapses and dendritic spines (Cingolani and Goda, 2008). Actin filament depolymerization reduces the size of gephyrin clusters in spinal neurons (Kirsch and Betz, 1995) and increases the lateral mobility in the postsynaptic density of subsets of GlyRs anchored at lower strength, raising the probability of their exit from the synapse (Charrier et al., 2006). Actin dynamics also control the mobility of the postsynaptic gephyrin cluster as a whole. At active synapses, postsynaptic gephyrin shows submicrom lateral motions around a central tether. Gephyrin movementsare two orders of magnitude slower than GlyRs motility (Hanus et al., 2006), however within minutes these movements result in gephyrin cluster reorganizations revealed by changes in the location of their "mass center". This suggests the potential for significant structural changes in the long term. Gephyrin cluster motion is reduced by actin cytoskeleton disruption and also by firing activity and glutamatergic neurotransmission, while inhibitory neurotransmission had a lower impact (Hanus et al., 2006). Excitatory inputs are known to rearrange the actin cytoskeleton (Cingolani and Goda, 2008), thus, excitatory activity could first increase cluster size and numbers signaling through specific kinases and then stabilize gephyrin cluster architecture through actions on the actin cytoskeleton.

At the molecular level, gephyrin has been shown to interact with several regulators of actin filaments such as, Mena/VASP (mammalian enabled/Vasodilator Stimulated Phosphoprotein), profilin and elongating factors (eEF1A) (Bausen et al., 2006; Becker et al., 2013; Giesemann et al., 2003; Mammoto et al., 1998; Murk et al., 2012; Neuhoff et al., 2005). Mena/VASP acts as an adaptor that links gephyrin 
to "uncapped" F-actin, and this interaction seems particularly important during stabilization of newly formed postsynaptic gephyrin patches in early synaptogenesis (Bausen et al., 2006). On the other hand profilins interact with $\mathrm{G}$-actin and are involved in actin filament elongation; they also directly interact with both Mena/VASP and gephyrin and they could alter postsynaptic gephyrin clustering in a manner regulated by activity (Giesemann et al., 2003; Mammoto et al., 1998; Murk et al., 2012; Neuhoff et al., 2005). More recently the elongation factor isoforms eEF1A1 and eEF1A2, with capacity to bundle and stabilize actin, were shown co-localized with gephyrin postsynaptically and their overexpression increased gephyrin clusters size and density, a mechanism that was also suggested to be modulated by activity (Becker et al., 2013). Thus, gephyrin directly interacts with a number of proteins that can anchor it to the postsynaptic actin cystoskeleton and also modulate F-actin elongation and stabilization in an activity dependent manner with the potential of inducing structural plasticity in the gephyrin patch.

A multiplicity of mechanisms can therefore be in use to induce changes in the organization of inhibitory synaptic postsynaptic regions and their gephyrin and receptor content in response to excitatory drive. These include increasing intracellular trafficking to the membrane, favoring the trapping of extrasynaptic GlyR-gephyrin units to postsynaptic clusters, increasing GlyR binding to gephyrin and GlyR retention inside gephyrin postsynaptic clusters and finally, stabilizing and shaping postsynaptic gephyrin-GlyR clusters through actions on the underlying actin cytoskeleton (Figure 3).

\section{RELATIONSHIPS BEWEEN NEUROLIGINS, COLLYBISTIN AND GEPHYRIN AND THE HETEROGENEITY OF INHIBITORY SYNAPSE MOLECULAR STRUCTURE, FORMATION AND MATURATION}

A variety of interactions between gephyrin, neuroligins and collybistin impart synapse heterogeneity to mechanisms that first form and then mature inhibitory synapses of different neurotransmitter phenotypes or location. Neuroligins are transmembrane proteins of the postsynaptic density that establish heterophyllic adhesions with presynaptic neurexins to facilitate synaptogenesis and synapse stabilization, maturation and function (Craig and Kang, 2007; Krueger et al., 2012; Sudhof, 2008). Their molecular diversity allows for a variety of interactions that initially are activity independent, however their persistent stabilization is later modulated by synaptic function. Four NLs have been identified in rodents that are further diversify by splice variants. Neuroligin-2 and NL-4 are predominantly associated with inhibitory synapses, while NL-1 associates with excitatory synapses and NL-3 co-localizes with either NL-2 or NL-1 at some inhibitory or excitatory synapses (Krueger et al., 2012). Scaffold proteins of excitatory synapses bind NL-1 (Krueger et al., 2012), and similarly gephyrin directly binds to NL-2 and NL4 (Hoon et al., 2011; Poulopoulos et al., 2009). Knockdown experiments demonstrated that NL-2 downregulation decreased gephyrin clustering and result in a 2-fold reduction in postsynaptic receptor accumulation reducing, but not abolishing, both GABAergic and glycinergic neurotransmission in forebrain and brainstem synapses (Poulopoulos et al., 2009). On the contrary, manipulations preventing gephyrin and receptor clustering did not block NL-2 from being recruited to the synapse, at least in hippocampal GABAergic synapses, suggesting NL-2 priming of the postsynaptic region that is gephyrinindependent. Moreover, NL-2 overexpression in non-neuronal cells can induce presynaptic differentiation in passing axons in the absence of postsynaptic receptor activity (Scheiffele et al., 2000). $\mathrm{GABA}_{\mathrm{A}}$ receptors are dispensable for NL-2 recruitment of gephyrin to postsynaptic regions, although later $\mathrm{GABA}_{A}$ receptor activation seems necessary for synapse stability (Patrizi et al., 2008). Thus, by difference to a model that uniquely requires "membrane GlyR activation" to initiate gephyrin clustering 
at glycinergic synapses, NL-2 was proposed to initiate recruitment of gephyrin to the postsynaptic region in GABAergic synapses (Poulopoulos et al., 2009). Neuroligins are also present at glycinergic synapses and therefore NL nucleation and GlyR activation could synergistically recruit gephyrin to specific membrane sites and the interactions between these molecules contribute to synapse stabilization and function. The balance between both mechanisms recruiting gephyrin to the synapse and their temporal sequence during synaptogenesis might be synapse specific. Further complexity arises because gephyrin interactions with NLs depend on synapse location, neurotransmitter type and subunit composition of the postsynaptic receptor. NL-2 knockdown in hippocampal neurons selectively decreases inhibitory synaptic transmission originated from perisomatic fast-spiking parvalbumin positive interneurons and not from somatostatin interneurons targeting the dendrite (Gibson et al., 2009; Jedlicka et al., 2011; Poulopoulos et al., 2009). Moreover, disruption of the gephyrin scaffold in CA1 pyramidal neurons prevents NL-2 accumulations in $\mathrm{GABA}_{A} \alpha 2$-containing synapses on the initial segment of the axon, but $\mathrm{NL}-2$ clustering is unaffected in cell body synapses with $\alpha 1$-containing $\mathrm{GABA}_{A}$ receptors (Panzanelli et al., 2011). In retina, NL-2 and NL-4 are specifically targeted to respectively GABAergic or glycinergic synapses (Hoon et al., 2009; Hoon et al., 2011). These data therefore show significant heterogeneity in NL function that could impart significant differences during formation and maturation of postsynaptic regions opposite to inhibitory synapses in distal vs proximal somatodendritic regions or using GlyRs vs $\mathrm{GABA}_{\mathrm{A}}$ receptors.

One important example are the many forebrain GABAergic synapses lacking GlyRs but that require gephyrin for postsynaptic $G_{A B A}$ receptor recruitment and clustering (other forebrain GABAergic inhibitory synapses can express gephyrin-independent $\mathrm{GABA}_{A}$ receptor synaptic clustering (Kneussel et al., 2001)). Gephyrin binding to $\mathrm{GABA}_{A}$ receptor subunits is of much lower affinity than GlyR binding (Tretter et al., 2012) and therefore this interaction is unlikely capable of stabilizing postsynaptic gephyrin scaffolds. In these synapses gephyrin tethering to the postsynaptic membrane is mediated by collybistin. Collybistin is a protein that binds gephyrin (Grosskreutz et al., 2001; Harvey et al., 2004; Kins et al., 2000) and has a pleckstrin-homology (PH) domain that interacts with phosphatidylinositol $(3,4,5)$ trisphosphate (PIP3) and serves as a membrane lipid anchor to bridge gephyrin to the membrane (Reddy-Alla et al., 2010). Targeted deletion of collybistin does not affect glycinergic synapses in spinal cord and brainstem but impairs GABAergic synapses in hippocampus (Papadopoulos et al., 2007). NLs are necessary for gephyrin membrane recruitment by collybistin. This is because all major forms of collybistin in the brain carry an SH3 domain that folds over the $\mathrm{PH}$ and gephyrin-binding domains keeping collybistin in an inactive conformation (Soykan et al., 2014). SH3 inhibition is relieved by binding to $\mathrm{NL}-2, \mathrm{NL}-4$, or the $\alpha 2$ subunit of the $\mathrm{GABA}_{\mathrm{A}}$ receptor and only thereafter gephyrin is recruited to the postsynaptic membrane (Hoon et al., 2011; Poulopoulos et al., 2009; Saiepour et al., 2010; Soykan et al., 2014). Collybistin was originally described as a Dbl-family guanine nucleotide exchange factor acting on Cdc42 raising the possibility of further interactions with the actin cytoskeleton (Kins et al., 2000). However, Cdc42 activity is not essential for gephyrin clustering at GABAergic synapses (Reddy-Alla et al., 2010) and possible variations in specificity of action at glycinergic synapses or the roles of alternative Rho-GTPases need to be further investigated. For example, collybistin binding to Rho-like GTPase TC10 was recently found to also relieve SH3 autoinhibition and favor collybistin-gephyrin membrane clustering (Mayer et al., 2013).

While collybistin function is critical at many GABAergic synapses the exact role of collybistin at glycinergic synapses is at present not fully understood since collybistin is dispensable for gephyrin 
anchoring in the postsynaptic membrane of glycinergic synapses. Collybistin associates with NL-4 and gephyrin at least in glycinergic synapses of the retina (Hoon et al., 2011). In these synapses, loss of NL-4 slows down the normal developmental subunit switch from $\alpha 2$-immature to $\alpha 1$-mature GlyRs affecting the normal functional development of glycinergic synapses towards faster kinetics (Hoon et al., 2011). Whether this deficit is specific to retina or also affects glycinergic synapses in brainstem and spinal cord is not known. Even if collybistin is not necessary for gephyrin cluster formation at glycinergic synapses it might have a role in shaping the structural maturation of the postsynaptic region. A recently proposed model suggests a fine regulation of gephyrin cluster size and numbers depending on the rates at which collybistin is trafficked on and off the membrane (Soykan et al., 2014). Neuroligin-collybistin interactions and collybistin mutants or modifications that increase the rate of collybistin membrane tethering events increase gephyrin cluster numbers, while collybistin dissociation from the membrane is controlled by the stability of the NL-collybistin-gephyrin complex and affects both the size and frequency of gephyrin clusters. The off-dissociation rate can be regulated by activity-dependent phosphorylation and dephosphorylation events targeting gephyrin and its protein partners. For example, phosphorylation of NL2 at a peptidyl-prolyl isomerase Pin1 consensus motif results in propyl-isomerization of phosphorylated serine 714 in NL-2 that induces a conformation change negatively affecting NL-2 binding to gephyrin (Antonelli et al., 2014). It is thus plausible that fine regulation of on and off rates of collybistin recruitment to the postsynaptic membrane might differentially affect the structure of the postsynaptic region and receptor densities.

In summary, the relations between NLs and gephyrin are complex and synapse-specific and could differentially affect somatic from dendritic synapses. In addition to providing alternative mechanisms for synapse formation and activity-dependent modulation of gephyrin clustering and GlyR subunit maturation. Neuroligins in conjunction with the gephyrin-binding protein collybistin are capable of generating diversity to mechanisms that recruit and stabilize gephyrin to postsynaptic regions according to differences in neurotransmitter phenotype or localization in different brain regions or neuronal compartments.

\section{INFLUENCES OF GEPHYRIN STRUCTURE IN RECEPTOR BINDING, SCAFFOLD ORGANIZATION AND REGULATION BY PHOSPHORYLATION}

Gephyrin binding to GlyRs and other proteins and gephyrin postsynaptic self-oligomerization are all critically dependent on the molecular structure of gephyrin (Figure 4). Gephyrin structure in turn depends on alternative splicing; the mouse geph gene contains 30 exons of which 10 are subject to alternative splicing creating a large multiplicity of gephyrin isoforms that display tissue and species specific expression patterns (Fritschy et al., 2008). Alternatively spliced cassettes influence gephyrin oligomerization and densities as well as receptor binding. One interesting spliced cassette (C5') excludes GlyRs from synapses by likely interfering with the stability and organization of the gephyrin scaffold (Meier et al., 2000; Meier and Grantyn, 2004; Bedet et al., 2006), while other splice variants bind GlyRs with different affinities and at different densities (Herweg and Schwarz, 2012; Paarmann et al., 2006; see Figure 4 and legend for further examples of splice variants with different gephyrin oligomerization properties and affinities for postsynaptic receptors). The significance of gephyrin isoforms and whether alternative splicing mechanisms are regulated by activity, are all aspects that require further investigation. However, one interesting study showed that glutamate-mediated seizure-induced 
alkalosis of hippocampal neurons affects gephyrin splicing and generates isoforms that lack a gephyrin domain (the G-domain) necessary for postsynaptic gephyrin aggregation and scaffold formation and thus acts as dominant negatives reducing postsynaptic gephyrin and $\mathrm{GABA}_{A}$ receptor clustering and diminishing inhibitory synaptic function in epileptic patients (Forstera et al., 2010).

The common P1 gephyrin variant that is abundant at many inhibitory synapses has three domains: an amino-terminal $\mathrm{G}$ domain, a carboxy-terminal $\mathrm{E}$ domain and a linker $\mathrm{C}$ domain (Fritschy et al., 2008; Figure 4). The $\mathrm{C}$ domain has numerous postranslational modification sites including many phosphorylation targets and binding sites for interacting proteins (Zacchi et al., 2014). It is also a target for $\mathrm{Ca}^{2+}$-dependent calpain-1 proteolytic degradation (Kawasaki et al., 1997; Tyagarajan et al., 2011). Cleavage disassembles $\mathrm{G}$ from $\mathrm{E}$ domains and prevents gephyrin synaptic aggregation. The $\mathrm{G}$ and $\mathrm{E}$ domains respectively trimerize and dimerize and blocking these molecular interactions also abolishes gephyrin clustering at the membrane (Saiyed et al., 2007; Sola et al., 2004). The three-fold G-domain and two-fold E-domain oligomerization lead to a model of gephyrin aggregation under the synapse in an hexagonal lattice (Kneussel and Betz, 2000; Sola et al., 2004). This scaffold is planar as proven by the constant distance to the membrane of single gephyrin epitopes recognized by monoclonal antibodies (Triller et al., 1985). The E dimerization interface specifically binds with high affinity the cytoplasmic loop of GlyR $\beta$ subunits (Kim et al., 2006; Meyer et al., 1995; Schrader et al., 2004), and this interaction is essential for the formation of submembrane gephyrin scaffolds at glycinergic synapses by increasing the stability of E-domain dimers and thus of the gephyrin assembly (Herweg and Schwarz, 2012; LardiStudler et al., 2007; Saiyed et al., 2007; Schrader et al., 2004). On the other hand, the G-domain trimerizes with high affinity independent of GlyR binding. Therefore in solution, gephyrin usually aggregates in trimers and GlyRs bound to gephyrin trimers are proposed to be used as transport cargo on microtubules towards the membrane. However, gephyrin trimers were also shown to display quite variable structure using atomic force microscopy and $\mathrm{x}$-ray scattering, and the high flexibility of gephyrin in solution was proposed to be the result of the many possible conformations of the C-linker region (Sander et al., 2013). Interestingly, the organization of the C-domain is controlled by phosphorylation, alternative splicing and gephyrin binding partners that can induce gephyrin to adopt variable conformations resulting in subsynaptic gephyrin scaffolds of different densities and structure (Herweg and Schwarz, 2012; Figure 4).

Therefore, while the E- and G-domain di- and trimerization are necessary for forming and stabilizing postsynaptic scaffolds and GlyR binding, C-linker phosphorylation is a major target for altering gephyrin aggregation and density. It has been known for a long time that gephyrin is a phosphoprotein targeted by endogenous kinases (Langosch et al., 1992), however the regulation of synaptic gephyrin cluster size and density through C-domain phosphorylation has become the focus of attention only in recent years. The emerging picture is one of significant complexity. Mass spectrometry identified more than 20 putative phosphorylation sites, the large majority in the C-domain (Herweg and Schwarz, 2012; Tyagarajan et al., 2013; Zacchi et al., 2014). It is likely that many of these sites interact, but recent studies have mainly focused on defining the roles of individual sites in gephyrin function. The previously reviewed CaMKII targets serine 305, close to the boundary between the $\mathrm{C}$ and $\mathrm{E}$ domains (Flores et al., 2015) and regulates gephyrin clustering in response to excitatory activity, GlyR activity and integrin activation. Interestingly, the adjacent serine 303 is also phosphorylated by CaMKII but was reported to have no discernable actions (Flores et al., 2015). Another important site is serine 270 targeted by Glycogen Synthase Kinase $3 \beta$ (GSK3 $\beta$ ) that when phosphorylated induces gephyrin $\mathrm{Ca}^{2+}$-dependent 
degradation by recruiting calpain 1 and results in gephyrin de-clustering (Tyagarajan et al., 2011). Recently, GSK3 $\beta$ was found to mediate a decrease in gephyrin cluster size after chronic AMPA treatment (8 hours) of neurons in primary culture (Rathgeber et al., 2015). This result is proof of principle that GSK3 $\beta$ can mediate actions downstream of excitatory receptor activation, however this treatment clearly caused also an overall non-physiologically response in the cultured neurons by increasing axonal gephyrin, a location from where it is usually excluded in mature cells (Rathgeber et al., 2015). The adjacent serine 268 is targeted by extracelluar signal-regulated kinase (ERK)-mediated phosphorylation and interacts with serine 270 regulating gephyrin cluster size (Tyagarajan et al., 2013). Another study, however, identified serine 270 as a critical site constitutively phosphorylated by Cyclin-dependent kinase 5 (Cdk5) in a collybistin-dependent manner and that when dephosphorylated reduces gephyrin cluster size (Kuhse et al., 2012). Therefore, serine 270 might integrate signals from different pathways to bi-directionally regulate gephyrin clustering, being the net result influenced by adjacent phosphorylation sites and perhaps the properties of the $\mathrm{Ca}^{2+}$ signal. Some of the phosphorylation targets first identified in the gephyrin molecule were several serines $(188,194$ and 200) adjacent to prolines that undergo "proline-directed" phosphorylation followed by Pin1-mediated isomerization (Zita et al., 2007). Pin1 binds to this region of the C-domain when it is phosphorylated and induces a conformation change that increases the affinity of gephyrin-GlyR binding enhancing GlyR retention and density and augmenting postsynaptic responses to glycine (Zita et al., 2007). Thus, Pin1-medited isomerization has opposite effects on inhibitory synaptic strength whether it targets sites on NL-2 or gephyrin, further underscoring the complexity of regulation of inhibitory synaptic function by phosphorylation mechanisms.

In summary, gephyrin is a phospho-protein targeted by a number of kinases including CaMKII, ERK, Cdk5 and GSK3 and phosphorylation-isomerization effectors (Pin1) that target the C-linker region and affect gephyrin structure, oligomerization and binding to GlyRs and other associated proteins (Zacchi et al., 2014). Many of these pathways are downstream of synaptic activity and therefore can mediate activitydependent modifications of gephyrin and GlyR recruitment, clustering and inhibitory synapse strength. They can also be modulated by convergent signaling pathways such as receptor tyrosine kinases. Brainderived neurotrophic factor (BDNF) acting on tropomyosin-related kinase B (TrkB) increases gephyrin clustering at the membrane (Chen et al., 2011; Wuchter et al., 2012) and this effect is mediated through signaling that includes both mitogen-activated protein kinase (MAPK) and phosphatidylinositol 3-kinase (Pi3K) pathways (Wuchter et al., 2012). The MAPK pathway activates ERK which directly targets gephyrin phosphorylation and clustering (Tyagarajan et al., 2013). The Pi3K pathway activates the mammalian target of rapamacyn (mTOR) and downregulates GSK3 $\beta$, the latter directly targeting gephyrin phosphorylation and degradation (Tyagarajan et al., 2011). The actions of mTOR are more complex. Gephyrin associates with mTOR through a binding motif similar to the GlyR $\beta$ subunit (Sabatini et al., 1999), thus mTOR activation releases gephyrin increasing its availability for clustering and GlyR binding (Wuchter et al., 2012). Gephyrin is therefore a major target where many phosphorylation-dependent signaling pathways converge to regulate postsynaptic receptor recruitment and inhibitory synaptic strength. Less is known about phosphatase activities on gephyrin; at least protein phosphatase 1 (PP1) has been shown to decrease gephyrin cluster size (Bausen et al., 2010) and to be downstream of tumor necrosis factor- $\alpha$ (TNF- $\alpha$ ), perhaps mediating the reductions in inhibitory synaptic strength observed during neuroinflammation (Pribiag and Stellwagen, 2013). Moreover, similar kinases and phosphatases can interact directly with GlyRs and $\mathrm{GABA}_{\mathrm{A}}$ receptors further modulating channel trafficking, membrane insertion, ion channel kinetics as well as these receptors retention in the postsynaptic scaffold (Nakamura et al., 2015; Smart, 1997; Talwar and Lynch, 2014). 


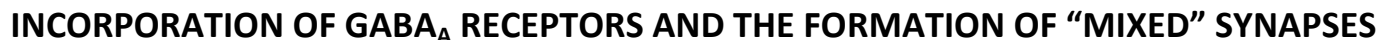

Many glycinergic synapses of the spinal cord and brainstem co-accumulate postsynaptically GlyRs and $G_{A B A_{A}}$ receptors; thus if the presynaptic terminal co-releases both inhibitory neurotransmitters the postsynaptic action is then mediated by both GlyRs and $\mathrm{GABA}_{\mathrm{A}}$ receptors in what has been referred to as "mixed" synapses (Chery and de Koninck, 1999; Jonas et al., 1998; Kotak et al., 1998; O'Brien and Berger, 1999). There are several variations to this theme. For example, a synapse might co-release both neurotransmitters but only GlyRs are clustered postsynaptically, in this case the postsynaptic action is exclusively glycinergic, but released GABA can still exert presynaptic auto-inhibition through $\mathrm{GABA}_{B}$ receptors (Lim et al., 2000). In other situations all synaptic boutons from a single axon co-release both neurotransmitters but the postsynaptic action can be either GABAergic or glycinergic on different targets depending on the type of receptor clustered postsynaptically (Dugue et al., 2005). Many mixed inhibitory synapses downregulate their GABAergic components and become only glycinergic through development (Awatramani et al., 2005; Gao et al., 2001; Keller et al., 2001; Kotak et al., 1998; Nabekura et al., 2004). In many situations this occurs because exclusion of postsynaptic $\mathrm{GABA}_{\mathrm{A}}$ receptors in mature synapses while co-release is maintained (Keller et al., 2001). In other synapses postsynaptic $\mathrm{GABA}_{\mathrm{A}}$ receptors are retained, but presynaptic GABA synthesis is downregulated diminishing the amount of GABA release (Ishibashi et al., 2013; Muller et al., 2006). However, in other neurons "mixed" GABA/glycine synapses are specifically preserved throughout development (Gonzalez-Forero and Alvarez, 2005). Finally, in neurons with complex dendritic arbors like motoneurons, inhibitory synapse enrichment in $\mathrm{GABA}_{A}$ receptors depends on the inhibitory synapse location and therefore the proportions of preserved "mixed" synapses varies along the dendrite (Lorenzo et al., 2007).

In mixed synapses the peak amplitude of the glycinergic component is usually larger than the GABAergic component and this occurs even when presynaptic GABA concentration is at the same level or even higher than glycine (Apostolides and Trussell, 2013). The larger conductance of GlyRs compared to $\mathrm{GABA}_{\mathrm{A}}$ receptors only partly explains the difference in peak amplitudes between glycine and GABA postsynaptic currents at mixed synapses, while the larger postsynaptic accumulation of GlyRs compared to $\mathrm{GABA}_{\mathrm{A}}$ receptors seems to account for most of the difference (Apostolides and Trussell, 2013). Thus, augmentation of peak amplitudes does not provide a sufficient "functional explanation" for retention of "mixed" synapses. On the other hand, the presence of GABAergic mechanisms at inhibitory synapses is important for lengthening the inhibitory synaptic action. GABAergic synaptic currents are of longer duration because the activation, de-activation and open times of $G A B A_{A}$ receptors of different subunit compositions all have longer kinetics than the commonly expressed $\alpha 1 \beta \mathrm{GlyR}$, although there are also some notable exceptions (Dumoulin et al., 2001; Rousseau et al., 2012).

During early development GABA-mediated lengthening of postsynaptic potentials might be advantageous when the main action of inhibitory synapses is depolarizing, driving many developmental processes through activation of L-type voltage-gated $\mathrm{Ca}^{2+}$ channels (Ben-Ari, 2001). In addition "mixed" synapses might increase inhibitory strength on immature neurons by inducing a long-lasting membrane "shunt" at developmental stages in which glycine and GABA are still partially depolarizing (Singer and Berger, 2000). Immature neurons typically display lower input resistances and longer space and time constants and therefore respond to excitatory currents with larger and longer depolarizations. In many of these neurons GABA/glycine "mixed" synapses disappear as the postsynaptic neurons mature. 
However, some "mixed" synapses over particular neurons or neuronal compartments are preserved likely because they are well adapted to specific properties of the local excitation. One example are the inhibitory synapses between cerebellar Golgi cells and Unipolar Brush Cells (UBC) in the vestibulocerebellum which display variable amounts of GABA/glycine co-transmission depending on the type of excitatory drive different types of UBCs receive (Rousseau et al., 2012). In the spinal cord, Renshaw cells preserve "mixed" inhibitory synapses while most other spinal interneurons and the motoneurons downregulate their GABAergic components (Gao et al., 2001; Gonzalez-Forero and Alvarez, 2005). In Renshaw cells the majority of the total inhibitory charge permeates through $G_{A B A_{A}}$ receptors, despite the lower peak amplitude of the GABAergic component compared to the glycinergic (Gonzalez-Forero and Alvarez, 2005). This long inhibition might be best adapted for controlling excitation in Renshaw cells, which is dominated by very long mixed nicotinic/NMDA EPSPs from motor axons and capable of evoking burst firing lasting hundreds of milliseconds (Eccles et al., 1954; Lamotte d'Incamps and Ascher, 2008; Mentis et al., 2005; Ross et al., 1976; Van Keulen, 1981). The effects of inhibition utilizing glycine or GABA only or mixed GABA/glycine neurotransmission was thoroughly studied on abducens motoneurons using pharmacology and neuronal modelling (Russier et al., 2002). The vestibulo-ocular inhibitory pathway on abducens motoneurons in the neonatal rat (P3 to P16) coreleases both inhibitory neurotransmitters, and as with many other "mixed" synapses, the glycinergic component is around 3 times larger in peak amplitude and the GABAergic component around 7 times slower. By stimulating this pathway in the presence of antagonists for GlyR or GABA $A_{A}$ receptors it was determined that despite its smaller peak amplitude, the effect on motoneuron firing was larger for the GABAergic component than for the glycinergic component, likely because the larger net inhibitory current carried by longer $\mathrm{GABA}_{\mathrm{A}}$ receptor openings. Moreover, inhibitory timing was complementary; the peak of glycinergic inhibition on motoneuron firing was around $6 \mathrm{~ms}$ after stimulation of the vestibulo-ocular pathway, while it was $15-20$ ms for the GABAergic component. Finally, modeling the amplitude and timing of IPSPs with different proportions of glycine and GABA neurotransmission revealed non-linear summations that depended on the relative proportions of the two inhibitory systems. Therefore, adjusting the relative proportions of GABA and glycine co-transmission provides for fine control of both the strength and timing of inhibition.

The regulation of $\mathrm{GABA}_{A}$ receptor content in glycinergic synapses is therefore critical for the formation of "mixed" synapses with appropriate glycinergic/GABAergic balance adapted to different functions, either during development or in the adult. In some uncommon situations GlyRs are excluded from "mixed" synapses after maturation and GABAergic mechanisms prevail (Meier et al., 2002). Developmental GlyR exclusion might be controlled by varying levels of expression of the gephyrin splice variant containing the $\mathrm{C} 5^{\prime}$ cassette (Meier and Grantyn, 2004). In contrast, the more common developmental removal of postsynaptic $\mathrm{GABA}_{\mathrm{A}}$ receptors from "mixed" synapses might be a consequence of the different affinities of gephyrin for GlyRs or $\mathrm{GABA}_{A}$ receptors. The nature of gephyrin binding to $G A B A_{A}$ receptors was unknown for a long time and newer methodologies had to be developed to reveal these interactions, which were then found to be rather weak compared to those between gephyrin and GlyRs (Tretter et al., 2012). While GlyRs interact through a high affinity binding motif in just the $\beta$ subunit, several different subunits of the $G_{A B A}$ receptor, including $\alpha 1-3$ and possibly also the $\beta 2-3$ subunits, bind gephyrin through low affinity interactions (Kowalczyk et al., 2013; Tretter et al., 2008; Tretter et al., 2011). The higher affinity of gephyrin for GlyRs might explain why GlyRs occur at higher numbers than $\mathrm{GABA}_{A}$ receptors at "mixed" synapses, as estimated by direct receptor counting using FRAP (Specht et al., 2013) or by comparing the peak amplitudes of quantal unitary postsynaptic 
currents. In agreement, $\mathrm{GABA}_{A}$ receptors diffusion over gephyrin clusters is faster than GlyRs suggesting lower retention (Specht et al., 2013). Interestingly, $G_{A B A}$ receptor subunits target a site in the gephyrin E-domain that is in close proximity to the GlyR $\beta$ subunit binding region (Maric et al., 2014a; Maric et al., 2011) setting a molecular competition mechanism that excludes $G_{A B A}$ receptors when GlyRs bind to gephyrin (Maric et al., 2014a). Thus, one possible explanation for the downregulation of GABA neurotransmission during development at "mixed" synapses is the increased expression with age of mature $\alpha 1 \beta$ GlyRs (Becker et al., 1988; Malosio et al., 1991; Sato et al., 1991) that could out-compete and displace $G_{A B A}$ receptors bound with lower affinities. A "natural experiment" tests this possibility due to the existence of spontaneous GlyR subunit mutations in mice that have been extensively studied as models of human hyperekplexia disorders (Rajendra and Schofield, 1995; Schaefer et al., 2012). In these mutant mice GlyR function is altered with and without changes in expression levels of $\alpha 1 \beta$ GlyRs. In the spasmodic mouse ( $s p d$ ) a single point mutation in the $\alpha 1$ subunit of the GlyR results in reduced agonist sensitivity and channel open time but without a reduction in GlyR expression; in the spastic mouse (spa) an intronic insertion in the $\beta$ subunit gene causes exon-skipping and reduces expression resulting in around 30\% decrease in GlyRs at the membrane; in the oscillator mouse (osc) a deletion of exon 8 in the $\alpha 1$ subunit results in almost complete absence of $\alpha 1 \beta$ GlyRs (Rajendra and Schofield, 1995; Schaefer et al., 2012). Interestingly, all three models show significant reductions in GlyR function in hypoglossal motoneurons detected as decreases in mIPSC amplitudes and frequency, however only in the spd and osc models there is an increase in GABAergic function shown as increased mIPSC peak amplitudes likely reflecting a higher accumulation of $\mathrm{GABA}_{A}$ receptors postsynaptically (Tadros et al., 2014). One interpretation of these results is that the lack of $\alpha 1 \beta$ GlyR expression in spa and oct mice preserves $\mathrm{GABA}_{A}$ receptor content postsynaptically, while incorporation of defective $\alpha 1 \beta$ GlyRs in the $s p d$ mouse does not, even though in all these mutants glycinergic neurotransmission is similarly significantly decreased.

These observations provide compelling evidence for competition between GlyR and $G A B A_{A}$ receptors for gephyrin binding sites in the postsynaptic scaffold, but other mechanisms can modify this process. The apparent affinities of each receptor for gephyrin can be significantly altered by coincident binding of multiple subunits (Maric et al., 2014b) which might be facilitated by specific gephyrin configurations of the scaffold set by alternative splicing or posttranslational modifications (Herweg and Schwarz, 2012). In addition, phosphorylation in both GlyRs and $\mathrm{GABA}_{A}$ receptors can also change their affinities to gephyrin (Mukherjee et al., 2011; Specht et al., 2011). These possibilities offer ample opportunities for fine modulation of the GlyR to $\mathrm{GABA}_{A}$ ratio in gephyrin clusters of different synapses. Finally, an important factor influencing the availability of gephyrin receptor binding sites is the size of the postsynaptic cluster. It is expected that gephyrin saturation by bound receptors decreases with increased cluster size and the number of gephyrin molecules. Accordingly, one of the highest levels of GABA $A$ and GlyR coexpression in the spinal cord is found over the large gephyrin clusters on the surface of Renshaw cells (Geiman et al., 2002). Increasing gephyrin cluster size might be another efficient mechanism to retain a significant number of $\mathrm{GABA}_{\mathrm{A}}$ receptors at glycinergic synapses.

\section{CONCLUDING REMARKS}

Gephyrin has emerged as a central regulator of inhibitory synaptic function controlling their structure, postsynaptic receptor retention, density, numbers and GlyR/GABA $A_{A}$ ratios. Gephyrin function is finely 
controlled by excitatory activity, depolarization and calcium signals upstream of a large number of activity-regulated kinases that target different residues in the gephyrin molecule. In addition, the actin cytoskeleton, neuroligins and alterative splicing mechanisms are also important modulators of the gephyrin scaffold and many act in synapse-specific manners. This complex function and regulation is quite different from the passive structural scaffold role initially envisioned for gephyrin when this molecule was first discovered. It also explains how inhibitory synapses locally adapt to the properties of the various types of excitatory mechanisms received by different neurons and dendritic regions. 


\section{References}

Aguayo LG, van Zundert B, Tapia JC, Carrasco MA, Alvarez FJ. 2004. Changes on the properties of glycine receptors during neuronal development. Brain Res Brain Res Rev 47(1-3):33-45.

Alvarez FJ, Dewey DE, Harrington DA, Fyffe RE. 1997. Cell-type specific organization of glycine receptor clusters in the mammalian spinal cord. J Comp Neurol 379(1):150-170.

Antonelli R, Pizzarelli R, Pedroni A, Fritschy JM, Del Sal G, Cherubini E, Zacchi P. 2014. Pin1-dependent signalling negatively affects GABAergic transmission by modulating neuroligin2/gephyrin interaction. Nat Commun 5:5066.

Apostolides PF, Trussell LO. 2013. Rapid, activity-independent turnover of vesicular transmitter content at a mixed glycine/GABA synapse. J Neurosci 33(11):4768-4781.

Awatramani GB, Turecek R, Trussell LO. 2005. Staggered development of GABAergic and glycinergic transmission in the MNTB. J Neurophysiol 93(2):819-828.

Barberis A, Petrini EM, Cherubini E. 2004. Presynaptic source of quantal size variability at GABAergic synapses in rat hippocampal neurons in culture. Eur J Neurosci 20(7):1803-1810.

Bausen M, Fuhrmann JC, Betz H, O'Sullivan G A. 2006. The state of the actin cytoskeleton determines its association with gephyrin: role of ena/VASP family members. Mol Cell Neurosci 31(2):376-386.

Bausen M, Weltzien F, Betz H, O'Sullivan GA. 2010. Regulation of postsynaptic gephyrin cluster size by protein phosphatase 1. Mol Cell Neurosci 44(3):201-209.

Becker CM, Hoch W, Betz H. 1988. Glycine receptor heterogeneity in rat spinal cord during postnatal development. EMBO J 7(12):3717-3726.

Becker M, Kuhse J, Kirsch J. 2013. Effects of two elongation factor $1 \mathrm{~A}$ isoforms on the formation of gephyrin clusters at inhibitory synapses in hippocampal neurons. Histochem Cell Biol 140(6):603-609.

Bedet C, Bruusgaard JC, Vergo S, Groth-Pedersen L, Eimer S, Triller A, Vannier C. 2006. Regulation of gephyrin assembly and glycine receptor synaptic stability. J Biol Chem 281(40):30046-30056.

Ben-Ari Y. 2001. Developing networks play a similar melody. Trends Neurosci 24(6):353-360.

Binder MD. 2002. Integration of synaptic and intrinsic dendritic currents in cat spinal motoneurons. Brain Res Brain Res Rev 40(1-3):1-8.

Bormann J, Hamill OP, Sakmann B. 1987. Mechanism of anion permeation through channels gated by glycine and gamma-aminobutyric acid in mouse cultured spinal neurones. J Physiol 385:243-286.

Calamai M, Specht CG, Heller J, Alcor D, Machado P, Vannier C, Triller A. 2009. Gephyrin oligomerization controls GlyR mobility and synaptic clustering. J Neurosci 29(24):7639-7648.

Cano R, Torres-Benito L, Tejero R, Biea Al, Ruiz R, Betz WJ, Tabares L. 2013. Structural and functional maturation of active zones in large synapses. Mol Neurobiol 47(1):209-219.

Charrier C, Ehrensperger MV, Dahan M, Levi S, Triller A. 2006. Cytoskeleton regulation of glycine receptor number at synapses and diffusion in the plasma membrane. J Neurosci 26(33):85028511.

Charrier C, Machado P, Tweedie-Cullen RY, Rutishauser D, Mansuy IM, Triller A. 2010. A crosstalk between beta1 and beta3 integrins controls glycine receptor and gephyrin trafficking at synapses. Nat Neurosci 13(11):1388-1395.

Chen Al, Nguyen CN, Copenhagen DR, Badurek S, Minichiello L, Ranscht B, Reichardt LF. 2011. TrkB (tropomyosin-related kinase $B$ ) controls the assembly and maintenance of GABAergic synapses in the cerebellar cortex. J Neurosci 31(8):2769-2780.

Chery N, de Koninck Y. 1999. Junctional versus extrajunctional glycine and GABA(A) receptor-mediated IPSCs in identified lamina I neurons of the adult rat spinal cord. J Neurosci 19(17):7342-7355.

Choii G, Ko J. 2015. Gephyrin: a central GABAergic synapse organizer. Exp Mol Med 47:e158. 
Cingolani LA, Goda Y. 2008. Actin in action: the interplay between the actin cytoskeleton and synaptic efficacy. Nat Rev Neurosci 9(5):344-356.

Craig AM, Kang Y. 2007. Neurexin-neuroligin signaling in synapse development. Curr Opin Neurobiol 17(1):43-52.

Dahan M, Levi S, Luccardini C, Rostaing P, Riveau B, Triller A. 2003. Diffusion dynamics of glycine receptors revealed by single-quantum dot tracking. Science 302(5644):442-445.

Dugue GP, Dumoulin A, Triller A, Dieudonne S. 2005. Target-dependent use of co-released inhibitory transmitters at central synapses. J Neurosci 25(28):6490-6498.

Dumoulin A, Triller A, Dieudonne S. 2001. IPSC kinetics at identified GABAergic and mixed GABAergic and glycinergic synapses onto cerebellar Golgi cells. J Neurosci 21(16):6045-6057.

Dutertre S, Becker CM, Betz H. 2012. Inhibitory glycine receptors: an update. J Biol Chem 287(48):4021640223.

Eccles JC, Fatt P, Koketsu K. 1954. Cholinergic and inhibitory synapses in a pathway from motor-axon collaterals to motoneurones. J Physiol 126(3):524-562.

Ehrensperger MV, Hanus C, Vannier C, Triller A, Dahan M. 2007. Multiple association states between glycine receptors and gephyrin identified by SPT analysis. Biophys J 92(10):3706-3718.

Faber DS, Young WS, Legendre P, Korn H. 1992. Intrinsic quantal variability due to stochastic properties of receptor-transmitter interactions. Science 258(5087):1494-1498.

Feng G, Tintrup H, Kirsch J, Nichol MC, Kuhse J, Betz H, Sanes JR. 1998. Dual requirement for gephyrin in glycine receptor clustering and molybdoenzyme activity. Science 282(5392):1321-1324.

Flores CE, Nikonenko I, Mendez P, Fritschy JM, Tyagarajan SK, Muller D. 2015. Activity-dependent inhibitory synapse remodeling through gephyrin phosphorylation. Proc Natl Acad Sci U S A 112(1):E65-72.

Forstera B, Belaidi AA, Juttner R, Bernert C, Tsokos M, Lehmann TN, Horn P, Dehnicke C, Schwarz G, Meier JC. 2010. Irregular RNA splicing curtails postsynaptic gephyrin in the cornu ammonis of patients with epilepsy. Brain 133(Pt 12):3778-3794.

Fritschy JM, Harvey RJ, Schwarz G. 2008. Gephyrin: where do we stand, where do we go? Trends Neurosci 31(5):257-264.

Gao BX, Stricker C, Ziskind-Conhaim L. 2001. Transition from GABAergic to glycinergic synaptic transmission in newly formed spinal networks. J Neurophysiol 86(1):492-502.

Geiman EJ, Knox MC, Alvarez FJ. 2000. Postnatal maturation of gephyrin/glycine receptor clusters on developing Renshaw cells. J Comp Neurol 426(1):130-142.

Geiman EJ, Zheng W, Fritschy JM, Alvarez FJ. 2002. Glycine and GABA(A) receptor subunits on Renshaw cells: relationship with presynaptic neurotransmitters and postsynaptic gephyrin clusters. J Comp Neurol 444(3):275-289.

Gibson JR, Huber KM, Sudhof TC. 2009. Neuroligin-2 deletion selectively decreases inhibitory synaptic transmission originating from fast-spiking but not from somatostatin-positive interneurons. J Neurosci 29(44):13883-13897.

Giesemann T, Schwarz G, Nawrotzki R, Berhorster K, Rothkegel M, Schluter K, Schrader N, Schindelin H, Mendel RR, Kirsch J, Jockusch BM. 2003. Complex formation between the postsynaptic scaffolding protein gephyrin, profilin, and Mena: a possible link to the microfilament system. J Neurosci 23(23):8330-8339.

Gomeza J, Ohno K, Betz H. 2003. Glycine transporter isoforms in the mammalian central nervous system: structures, functions and therapeutic promises. Curr Opin Drug Discov Devel 6(5):675682.

Gonzalez-Forero D, Alvarez FJ. 2005. Differential postnatal maturation of GABAA, glycine receptor, and mixed synaptic currents in Renshaw cells and ventral spinal interneurons. J Neurosci 25(8):20102023. 
Gonzalez-Forero D, Pastor AM, Geiman EJ, Benitez-Temino B, Alvarez FJ. 2005. Regulation of gephyrin cluster size and inhibitory synaptic currents on Renshaw cells by motor axon excitatory inputs. J Neurosci 25(2):417-429.

Grosskreutz Y, Hermann A, Kins S, Fuhrmann JC, Betz H, Kneussel M. 2001. Identification of a gephyrinbinding motif in the GDP/GTP exchange factor collybistin. Biol Chem 382(10):1455-1462.

Hajos N, Nusser Z, Rancz EA, Freund TF, Mody I. 2000. Cell type- and synapse-specific variability in synaptic GABAA receptor occupancy. Eur J Neurosci 12(3):810-818.

Hanus C, Ehrensperger MV, Triller A. 2006. Activity-dependent movements of postsynaptic scaffolds at inhibitory synapses. J Neurosci 26(17):4586-4595.

Hanus C, Vannier C, Triller A. 2004. Intracellular association of glycine receptor with gephyrin increases its plasma membrane accumulation rate. J Neurosci 24(5):1119-1128.

Harvey K, Duguid IC, Alldred MJ, Beatty SE, Ward H, Keep NH, Lingenfelter SE, Pearce BR, Lundgren J, Owen MJ, Smart TG, Luscher B, Rees MI, Harvey RJ. 2004. The GDP-GTP exchange factor collybistin: an essential determinant of neuronal gephyrin clustering. J Neurosci 24(25):58165826.

Harvey RJ, Topf M, Harvey K, Rees MI. 2008. The genetics of hyperekplexia: more than startle! Trends Genet 24(9):439-447.

Heckman CJ, Hyngstrom AS, Johnson MD. 2008. Active properties of motoneurone dendrites: diffuse descending neuromodulation, focused local inhibition. J Physiol 586(5):1225-1231.

Herweg J, Schwarz G. 2012. Splice-specific glycine receptor binding, folding, and phosphorylation of the scaffolding protein gephyrin. J Biol Chem 287(16):12645-12656.

Holderith N, Lorincz A, Katona G, Rozsa B, Kulik A, Watanabe M, Nusser Z. 2012. Release probability of hippocampal glutamatergic terminals scales with the size of the active zone. Nat Neurosci 15(7):988-997.

Hoon M, Bauer G, Fritschy JM, Moser T, Falkenburger BH, Varoqueaux F. 2009. Neuroligin 2 controls the maturation of GABAergic synapses and information processing in the retina. J Neurosci 29(25):8039-8050.

Hoon M, Soykan T, Falkenburger B, Hammer M, Patrizi A, Schmidt KF, Sassoe-Pognetto M, Lowel S, Moser T, Taschenberger H, Brose N, Varoqueaux F. 2011. Neuroligin-4 is localized to glycinergic postsynapses and regulates inhibition in the retina. Proc Natl Acad Sci U S A 108(7):3053-3058.

Hounsgaard J, Hultborn H, Jespersen B, Kiehn O. 1988. Bistability of alpha-motoneurones in the decerebrate cat and in the acute spinal cat after intravenous 5-hydroxytryptophan. J Physiol 405:345-367.

lansek R, Redman SJ. 1973. The amplitude, time course and charge of unitary excitatory post-synaptic potentials evoked in spinal motoneurone dendrites. J Physiol 234(3):665-688.

Isaacson JS, Walmsley B. 1995. Counting quanta: direct measurements of transmitter release at a central synapse. Neuron 15(4):875-884.

Ishibashi H, Yamaguchi J, Nakahata Y, Nabekura J. 2013. Dynamic regulation of glycine-GABA cotransmission at spinal inhibitory synapses by neuronal glutamate transporter. J Physiol 591(16):3821-3832.

Jack JJ, Redman SJ, Wong K. 1981. The components of synaptic potentials evoked in cat spinal motoneurones by impulses in single group la afferents. J Physiol 321:65-96.

Jedlicka P, Hoon M, Papadopoulos T, Vlachos A, Winkels R, Poulopoulos A, Betz H, Deller T, Brose N, Varoqueaux F, Schwarzacher SW. 2011. Increased dentate gyrus excitability in neuroligin-2deficient mice in vivo. Cereb Cortex 21(2):357-367.

Jiang Z, Rempel J, Li J, Sawchuk MA, Carlin KP, Brownstone RM. 1999. Development of L-type calcium channels and a nifedipine-sensitive motor activity in the postnatal mouse spinal cord. Eur J Neurosci 11(10):3481-3487. 
Jonas P, Bischofberger J, Sandkuhler J. 1998. Corelease of two fast neurotransmitters at a central synapse. Science 281(5375):419-424.

Kasugai Y, Swinny JD, Roberts JD, Dalezios Y, Fukazawa Y, Sieghart W, Shigemoto R, Somogyi P. 2010. Quantitative localisation of synaptic and extrasynaptic GABAA receptor subunits on hippocampal pyramidal cells by freeze-fracture replica immunolabelling. Eur J Neurosci 32(11):1868-1888.

Kawasaki BT, Hoffman KB, Yamamoto RS, Bahr BA. 1997. Variants of the receptor/channel clustering molecule gephyrin in brain: distinct distribution patterns, developmental profiles, and proteolytic cleavage by calpain. J Neurosci Res 49(3):381-388.

Keller AF, Coull JA, Chery N, Poisbeau P, De Koninck Y. 2001. Region-specific developmental specialization of GABA-glycine cosynapses in laminas I-II of the rat spinal dorsal horn. J Neurosci 21(20):7871-7880.

Kim EY, Schrader N, Smolinsky B, Bedet C, Vannier C, Schwarz G, Schindelin H. 2006. Deciphering the structural framework of glycine receptor anchoring by gephyrin. EMBO J 25(6):1385-1395.

Kins S, Betz H, Kirsch J. 2000. Collybistin, a newly identified brain-specific GEF, induces submembrane clustering of gephyrin. Nat Neurosci 3(1):22-29.

Kirsch J, Betz H. 1995. The postsynaptic localization of the glycine receptor-associated protein gephyrin is regulated by the cytoskeleton. J Neurosci 15(6):4148-4156.

Kirsch J, Betz H. 1998. Glycine-receptor activation is required for receptor clustering in spinal neurons. Nature 392(6677):717-720.

Kirsch J, Wolters I, Triller A, Betz H. 1993. Gephyrin antisense oligonucleotides prevent glycine receptor clustering in spinal neurons. Nature 366(6457):745-748.

Kneussel M, Betz H. 2000. Clustering of inhibitory neurotransmitter receptors at developing postsynaptic sites: the membrane activation model. Trends Neurosci 23(9):429-435.

Kneussel M, Brandstatter JH, Gasnier B, Feng G, Sanes JR, Betz H. 2001. Gephyrin-independent clustering of postsynaptic GABA(A) receptor subtypes. Mol Cell Neurosci 17(6):973-982.

Korn H, Bausela F, Charpier S, Faber DS. 1993. Synaptic noise and multiquantal release at dendritic synapses. J Neurophysiol 70(3):1249-1254.

Korn H, Mallet A, Triller A, Faber DS. 1982. Transmission at a central inhibitory synapse. II. Quantal description of release, with a physical correlate for binomial n. J Neurophysiol 48(3):679-707.

Kotak VC, Korada S, Schwartz IR, Sanes DH. 1998. A developmental shift from GABAergic to glycinergic transmission in the central auditory system. J Neurosci 18(12):4646-4655.

Kowalczyk S, Winkelmann A, Smolinsky B, Forstera B, Neundorf I, Schwarz G, Meier JC. 2013. Direct binding of GABAA receptor beta2 and beta3 subunits to gephyrin. Eur J Neurosci 37(4):544-554.

Krueger DD, Tuffy LP, Papadopoulos T, Brose N. 2012. The role of neurexins and neuroligins in the formation, maturation, and function of vertebrate synapses. Curr Opin Neurobiol 22(3):412-422.

Kruk PJ, Korn H, Faber DS. 1997. The effects of geometrical parameters on synaptic transmission: a Monte Carlo simulation study. Biophys J 73(6):2874-2890.

Kuhse J, Kalbouneh H, Schlicksupp A, Mukusch S, Nawrotzki R, Kirsch J. 2012. Phosphorylation of gephyrin in hippocampal neurons by cyclin-dependent kinase CDK5 at Ser-270 is dependent on collybistin. J Biol Chem 287(37):30952-30966.

Lamotte d'Incamps B, Ascher P. 2008. Four excitatory postsynaptic ionotropic receptors coactivated at the motoneuron-Renshaw cell synapse. J Neurosci 28(52):14121-14131.

Langosch D, Hoch W, Betz H. 1992. The 93 kDa protein gephyrin and tubulin associated with the inhibitory glycine receptor are phosphorylated by an endogenous protein kinase. FEBS Lett 298(2-3):113-117. 
Lardi-Studler B, Smolinsky B, Petitjean CM, Koenig F, Sidler C, Meier JC, Fritschy JM, Schwarz G. 2007. Vertebrate-specific sequences in the gephyrin E-domain regulate cytosolic aggregation and postsynaptic clustering. J Cell Sci 120(Pt 8):1371-1382.

Latal AT, Kremer T, Gomeza J, Eulenburg V, Hulsmann S. 2010. Development of synaptic inhibition in glycine transporter 2 deficient mice. Mol Cell Neurosci 44(4):342-352.

Legendre P. 2001. The glycinergic inhibitory synapse. Cell Mol Life Sci 58(5-6):760-793.

Levi S, Schweizer C, Bannai H, Pascual O, Charrier C, Triller A. 2008. Homeostatic regulation of synaptic GlyR numbers driven by lateral diffusion. Neuron 59(2):261-273.

Levi S, Vannier C, Triller A. 1998. Strychnine-sensitive stabilization of postsynaptic glycine receptor clusters. J Cell Sci 111 ( Pt 3):335-345.

Lim R, Alvarez FJ, Walmsley B. 1999. Quantal size is correlated with receptor cluster area at glycinergic synapses in the rat brainstem. J Physiol 516 ( Pt 2):505-512.

Lim R, Alvarez FJ, Walmsley B. 2000. GABA mediates presynaptic inhibition at glycinergic synapses in a rat auditory brainstem nucleus. J Physiol 525 Pt 2:447-459.

Lorenzo LE, Russier M, Barbe A, Fritschy JM, Bras H. 2007. Differential organization of gammaaminobutyric acid type $A$ and glycine receptors in the somatic and dendritic compartments of rat abducens motoneurons. J Comp Neurol 504(2):112-126.

Lynch JW. 2009. Native glycine receptor subtypes and their physiological roles. Neuropharmacology 56(1):303-309.

Lynch JW, Callister RJ. 2006. Glycine receptors: a new therapeutic target in pain pathways. Curr Opin Investig Drugs 7(1):48-53.

Maas C, Belgardt D, Lee HK, Heisler FF, Lappe-Siefke C, Magiera MM, van Dijk J, Hausrat TJ, Janke C, Kneussel M. 2009. Synaptic activation modifies microtubules underlying transport of postsynaptic cargo. Proc Natl Acad Sci U S A 106(21):8731-8736.

Maas C, Tagnaouti N, Loebrich S, Behrend B, Lappe-Siefke C, Kneussel M. 2006. Neuronal cotransport of glycine receptor and the scaffold protein gephyrin. J Cell Biol 172(3):441-451.

Magee JC. 2000. Dendritic integration of excitatory synaptic input. Nat Rev Neurosci 1(3):181-190.

Malosio ML, Marqueze-Pouey B, Kuhse J, Betz H. 1991. Widespread expression of glycine receptor subunit mRNAs in the adult and developing rat brain. EMBO J 10(9):2401-2409.

Mammoto A, Sasaki T, Asakura T, Hotta I, Imamura H, Takahashi K, Matsuura Y, Shirao T, Takai Y. 1998. Interactions of drebrin and gephyrin with profilin. Biochem Biophys Res Commun 243(1):86-89.

Maric HM, Kasaragod VB, Hausrat TJ, Kneussel M, Tretter V, Stromgaard K, Schindelin H. 2014a. Molecular basis of the alternative recruitment of $\mathrm{GABA}(\mathrm{A})$ versus glycine receptors through gephyrin. Nat Commun 5:5767.

Maric HM, Kasaragod VB, Schindelin H. 2014b. Modulation of gephyrin-glycine receptor affinity by multivalency. ACS Chem Biol 9(11):2554-2562.

Maric HM, Mukherjee J, Tretter V, Moss SJ, Schindelin H. 2011. Gephyrin-mediated gammaaminobutyric acid type $A$ and glycine receptor clustering relies on a common binding site. J Biol Chem 286(49):42105-42114.

Marsden KC, Shemesh A, Bayer KU, Carroll RC. 2010. Selective translocation of Ca2+/calmodulin protein kinase Ilalpha (CaMKIlalpha) to inhibitory synapses. Proc Natl Acad Sci U S A 107(47):2055920564.

Mayer S, Kumar R, Jaiswal M, Soykan T, Ahmadian MR, Brose N, Betz H, Rhee JS, Papadopoulos T. 2013. Collybistin activation by GTP-TC10 enhances postsynaptic gephyrin clustering and hippocampal GABAergic neurotransmission. Proc Natl Acad Sci U S A 110(51):20795-20800.

McGeachie AB, Cingolani LA, Goda Y. 2011. Stabilising influence: integrins in regulation of synaptic plasticity. Neurosci Res 70(1):24-29. 
Meier J, De Chaldee M, Triller A, Vannier C. 2000. Functional heterogeneity of gephyrins. Mol Cell Neurosci 16(5):566-577.

Meier J, Grantyn R. 2004. A gephyrin-related mechanism restraining glycine receptor anchoring at GABAergic synapses. J Neurosci 24(6):1398-1405.

Meier J, Juttner R, Kirischuk S, Grantyn R. 2002. Synaptic anchoring of glycine receptors in developing collicular neurons under control of metabotropic glutamate receptor activity. Mol Cell Neurosci 21(2):324-340.

Meier J, Vannier C, Serge A, Triller A, Choquet D. 2001. Fast and reversible trapping of surface glycine receptors by gephyrin. Nat Neurosci 4(3):253-260.

Mentis GZ, Alvarez FJ, Bonnot A, Richards DS, Gonzalez-Forero D, Zerda R, O'Donovan MJ. 2005. Noncholinergic excitatory actions of motoneurons in the neonatal mammalian spinal cord. Proc Natl Acad Sci U S A 102(20):7344-7349.

Meyer G, Kirsch J, Betz H, Langosch D. 1995. Identification of a gephyrin binding motif on the glycine receptor beta subunit. Neuron 15(3):563-572.

Mody I, Pearce RA. 2004. Diversity of inhibitory neurotransmission through GABA(A) receptors. Trends Neurosci 27(9):569-575.

Moore NJ, Bhumbra GS, Foster JD, Beato M. 2015. Synaptic Connectivity between Renshaw Cells and Motoneurons in the Recurrent Inhibitory Circuit of the Spinal Cord. J Neurosci 35(40):1367313686.

Mukherjee J, Kretschmannova K, Gouzer G, Maric HM, Ramsden S, Tretter V, Harvey K, Davies PA, Triller A, Schindelin H, Moss SJ. 2011. The residence time of GABA(A)Rs at inhibitory synapses is determined by direct binding of the receptor alpha1 subunit to gephyrin. $J$ Neurosci 31(41):14677-14687.

Muller E, Le Corronc H, Triller A, Legendre P. 2006. Developmental dissociation of presynaptic inhibitory neurotransmitter and postsynaptic receptor clustering in the hypoglossal nucleus. Mol Cell Neurosci 32(3):254-273.

Murk K, Wittenmayer N, Michaelsen-Preusse K, Dresbach T, Schoenenberger CA, Korte M, Jockusch BM, Rothkegel M. 2012. Neuronal profilin isoforms are addressed by different signalling pathways. PLoS One 7(3):e34167.

Nabekura J, Katsurabayashi S, Kakazu Y, Shibata S, Matsubara A, Jinno S, Mizoguchi Y, Sasaki A, Ishibashi H. 2004. Developmental switch from GABA to glycine release in single central synaptic terminals. Nat Neurosci 7(1):17-23.

Nakamura Y, Darnieder LM, Deeb TZ, Moss SJ. 2015. Regulation of GABAARs by phosphorylation. Adv Pharmacol 72:97-146.

Neuhoff H, Sassoe-Pognetto M, Panzanelli P, Maas C, Witke W, Kneussel M. 2005. The actin-binding protein profilin I is localized at synaptic sites in an activity-regulated manner. Eur J Neurosci 21(1):15-25.

Niwa F, Bannai H, Arizono M, Fukatsu K, Triller A, Mikoshiba K. 2012. Gephyrin-independent GABA(A)R mobility and clustering during plasticity. PLoS One 7(4):e36148.

Nusser Z, Cull-Candy S, Farrant M. 1997. Differences in synaptic GABA(A) receptor number underlie variation in GABA mini amplitude. Neuron 19(3):697-709.

Nusser Z, Hajos N, Somogyi P, Mody I. 1998. Increased number of synaptic GABA(A) receptors underlies potentiation at hippocampal inhibitory synapses. Nature 395(6698):172-177.

O'Brien JA, Berger AJ. 1999. Cotransmission of GABA and glycine to brain stem motoneurons. J Neurophysiol 82(3):1638-1641.

Oleskevich S, Alvarez FJ, Walmsley B. 1999. Glycinergic miniature synaptic currents and receptor cluster sizes differ between spinal cord interneurons. J Neurophysiol 82(1):312-319. 
Paarmann I, Schmitt B, Meyer B, Karas M, Betz H. 2006. Mass spectrometric analysis of glycine receptorassociated gephyrin splice variants. J Biol Chem 281(46):34918-34925.

Paarman I, Saiyed T, Schmitt B, Betz H. 2006. Gephyrin: does splicing affect its function. Biochem Soc Trans 34(Pt1):45-47.

Panzanelli P, Gunn BG, Schlatter MC, Benke D, Tyagarajan SK, Scheiffele P, Belelli D, Lambert JJ, Rudolph $U$, Fritschy JM. 2011. Distinct mechanisms regulate GABAA receptor and gephyrin clustering at perisomatic and axo-axonic synapses on CA1 pyramidal cells. J Physiol 589(Pt 20):4959-4980.

Papadopoulos T, Korte M, Eulenburg V, Kubota H, Retiounskaia M, Harvey RJ, Harvey K, O'Sullivan GA, Laube B, Hulsmann S, Geiger JR, Betz H. 2007. Impaired GABAergic transmission and altered hippocampal synaptic plasticity in collybistin-deficient mice. EMBO J 26(17):3888-3899.

Patrizi A, Scelfo B, Viltono L, Briatore F, Fukaya M, Watanabe M, Strata P, Varoqueaux F, Brose N, Fritschy JM, Sassoe-Pognetto M. 2008. Synapse formation and clustering of neuroligin-2 in the absence of GABAA receptors. Proc Natl Acad Sci U S A 105(35):13151-13156.

Pfeiffer F, Graham D, Betz H. 1982. Purification by affinity chromatography of the glycine receptor of rat spinal cord. J Biol Chem 257(16):9389-9393.

Poulopoulos A, Aramuni G, Meyer G, Soykan T, Hoon M, Papadopoulos T, Zhang M, Paarmann I, Fuchs C, Harvey K, Jedlicka P, Schwarzacher SW, Betz H, Harvey RJ, Brose N, Zhang W, Varoqueaux F. 2009. Neuroligin 2 drives postsynaptic assembly at perisomatic inhibitory synapses through gephyrin and collybistin. Neuron 63(5):628-642.

Pribiag H, Stellwagen D. 2013. TNF-alpha downregulates inhibitory neurotransmission through protein phosphatase 1-dependent trafficking of GABA(A) receptors. J Neurosci 33(40):15879-15893.

Pulido C, Trigo FF, Llano I, Marty A. 2015. Vesicular release statistics and unitary postsynaptic current at single GABAergic synapses. Neuron 85(1):159-172.

Quinlan KA, Schuster JE, Fu R, Siddique T, Heckman CJ. 2011. Altered postnatal maturation of electrical properties in spinal motoneurons in a mouse model of amyotrophic lateral sclerosis. J Physiol 589(Pt 9):2245-2260.

Rajendra S, Schofield PR. 1995. Molecular mechanisms of inherited startle syndromes. Trends Neurosci 18(2):80-82.

Rathgeber L, Gromova KV, Schaefer I, Breiden P, Lohr C, Kneussel M. 2015. GSK3 and KIF5 regulate activity-dependent sorting of gephyrin between axons and dendrites. Eur J Cell Biol 94(3-4):173178.

Reddy-Alla S, Schmitt B, Birkenfeld J, Eulenburg V, Dutertre S, Bohringer C, Gotz M, Betz H, Papadopoulos T. 2010. PH-domain-driven targeting of collybistin but not Cdc42 activation is required for synaptic gephyrin clustering. Eur J Neurosci 31(7):1173-1184.

Renshaw B. 1946. Central effects of centripetal impulses in axons of spinal ventral roots. J Neurophysiol 9:191-204.

Ross HG, Cleveland S, Haase J. 1976. Quantitative relation between discharge frequencies of a Renshaw cell and an intracellularly depolarized motoneuron. Neurosci Lett 3(3):129-132.

Rousseau CV, Dugue GP, Dumoulin A, Mugnaini E, Dieudonne S, Diana MA. 2012. Mixed inhibitory synaptic balance correlates with glutamatergic synaptic phenotype in cerebellar unipolar brush cells. J Neurosci 32(13):4632-4644.

Rousseau F, Aubrey KR, Supplisson S. 2008. The glycine transporter GlyT2 controls the dynamics of synaptic vesicle refilling in inhibitory spinal cord neurons. J Neurosci 28(39):9755-9768.

Russier M, Kopysova IL, Ankri N, Ferrand N, Debanne D. 2002. GABA and glycine co-release optimizes functional inhibition in rat brainstem motoneurons in vitro. J Physiol 541(Pt 1):123-137.

Sabatini DM, Barrow RK, Blackshaw S, Burnett PE, Lai MM, Field ME, Bahr BA, Kirsch J, Betz H, Snyder $\mathrm{SH}$. 1999. Interaction of RAFT1 with gephyrin required for rapamycin-sensitive signaling. Science 284(5417):1161-1164. 
Saiepour L, Fuchs C, Patrizi A, Sassoe-Pognetto M, Harvey RJ, Harvey K. 2010. Complex role of collybistin and gephyrin in GABAA receptor clustering. J Biol Chem 285(38):29623-29631.

Saiyed T, Paarmann I, Schmitt B, Haeger S, Sola M, Schmalzing G, Weissenhorn W, Betz H. 2007. Molecular basis of gephyrin clustering at inhibitory synapses: role of $\mathrm{G}$ - and $\mathrm{E}$-domain interactions. J Biol Chem 282(8):5625-5632.

Sander B, Tria G, Shkumatov AV, Kim EY, Grossmann JG, Tessmer I, Svergun DI, Schindelin H. 2013. Structural characterization of gephyrin by AFM and SAXS reveals a mixture of compact and extended states. Acta Crystallogr D Biol Crystallogr 69(Pt 10):2050-2060.

Sassoe-Pognetto M, Panzanelli P, Sieghart W, Fritschy JM. 2000. Colocalization of multiple GABA(A) receptor subtypes with gephyrin at postsynaptic sites. J Comp Neurol 420(4):481-498.

Sato K, Zhang JH, Saika T, Sato M, Tada K, Tohyama M. 1991. Localization of glycine receptor alpha 1 subunit mRNA-containing neurons in the rat brain: an analysis using in situ hybridization histochemistry. Neuroscience 43(2-3):381-395.

Schaefer N, Langlhofer G, Kluck CJ, Villmann C. 2013. Glycine receptor mouse mutants: model systems for human hyperekplexia. Br J Pharmacol 170(5):933-952.

Schaefer N, Vogel N, Villmann C. 2012. Glycine receptor mutants of the mouse: what are possible routes of inhibitory compensation? Front Mol Neurosci 5:98.

Scheiffele P, Fan J, Choih J, Fetter R, Serafini T. 2000. Neuroligin expressed in nonneuronal cells triggers presynaptic development in contacting axons. Cell 101(6):657-669.

Schikorski T, Stevens CF. 1997. Quantitative ultrastructural analysis of hippocampal excitatory synapses. J Neurosci 17(15):5858-5867.

Schrader N, Kim EY, Winking J, Paulukat J, Schindelin H, Schwarz G. 2004. Biochemical characterization of the high affinity binding between the glycine receptor and gephyrin. J Biol Chem 279(18):1873318741.

Sheng J, He L, Zheng H, Xue L, Luo F, Shin W, Sun T, Kuner T, Yue DT, Wu LG. 2012. Calcium-channel number critically influences synaptic strength and plasticity at the active zone. Nat Neurosci 15(7):998-1006.

Singer JH, Berger AJ. 1999. Contribution of single-channel properties to the time course and amplitude variance of quantal glycine currents recorded in rat motoneurons. J Neurophysiol 81(4):16081616.

Singer JH, Berger AJ. 2000. Development of inhibitory synaptic transmission to motoneurons. Brain Res Bull 53(5):553-560.

Smart TG. 1997. Regulation of excitatory and inhibitory neurotransmitter-gated ion channels by protein phosphorylation. Curr Opin Neurobiol 7(3):358-367.

Smith SM, Zorec R, McBurney RN. 1989. Conductance states activated by glycine and GABA in rat cultured spinal neurones. J Membr Biol 108(1):45-52.

Sola M, Bavro VN, Timmins J, Franz T, Ricard-Blum S, Schoehn G, Ruigrok RW, Paarmann I, Saiyed T, O'Sullivan GA, Schmitt B, Betz H, Weissenhorn W. 2004. Structural basis of dynamic glycine receptor clustering by gephyrin. EMBO J 23(13):2510-2519.

Soykan T, Schneeberger D, Tria G, Buechner C, Bader N, Svergun D, Tessmer I, Poulopoulos A, Papadopoulos T, Varoqueaux F, Schindelin H, Brose N. 2014. A conformational switch in collybistin determines the differentiation of inhibitory postsynapses. EMBO J 33(18):2113-2133.

Specht CG, Grunewald N, Pascual O, Rostgaard N, Schwarz G, Triller A. 2011. Regulation of glycine receptor diffusion properties and gephyrin interactions by protein kinase C. EMBO J 30(18):3842-3853.

Specht CG, Izeddin I, Rodriguez PC, El Beheiry M, Rostaing P, Darzacq X, Dahan M, Triller A. 2013. Quantitative nanoscopy of inhibitory synapses: counting gephyrin molecules and receptor binding sites. Neuron 79(2):308-321. 
Stallmeyer B, Schwarz G, Schulze J, Nerlich A, Reiss J, Kircsh J, Mendell RR. 1999. The neurotransmitter receptor-anchoring proetin gephyrin reconstitutes molybdenum cofactor biosyntheis in bacteria, plants and mammalian cells. Proc Natl Acad Sci U S A 96(4):1333-1338

Sudhof TC. 2008. Neuroligins and neurexins link synaptic function to cognitive disease. Nature 455(7215):903-911.

Suwa H, Saint-Amant L, Triller A, Drapeau P, Legendre P. 2001. High-affinity zinc potentiation of inhibitory postsynaptic glycinergic currents in the zebrafish hindbrain. J Neurophysiol 85(2):912925.

Tadros MA, Farrell KE, Schofield PR, Brichta AM, Graham BA, Fuglevand AJ, Callister RJ. 2014. Intrinsic and synaptic homeostatic plasticity in motoneurons from mice with glycine receptor mutations. J Neurophysiol 111(7):1487-1498.

Takahashi T, Momiyama A, Hirai K, Hishinuma F, Akagi H. 1992. Functional correlation of fetal and adult forms of glycine receptors with developmental changes in inhibitory synaptic receptor channels. Neuron 9(6):1155-1161.

Talwar S, Lynch JW. 2014. Phosphorylation mediated structural and functional changes in pentameric ligand-gated ion channels: implications for drug discovery. Int J Biochem Cell Biol 53:218-223.

Taschenberger H, Leao RM, Rowland KC, Spirou GA, von Gersdorff H. 2002. Optimizing synaptic architecture and efficiency for high-frequency transmission. Neuron 36(6):1127-1143.

Titmus MJ, Korn H, Faber DS. 1996. Diffusion, not uptake, limits glycine concentration in the synaptic cleft. J Neurophysiol 75(4):1738-1752.

Tretter V, Jacob TC, Mukherjee J, Fritschy JM, Pangalos MN, Moss SJ. 2008. The clustering of GABA(A) receptor subtypes at inhibitory synapses is facilitated via the direct binding of receptor alpha 2 subunits to gephyrin. J Neurosci 28(6):1356-1365.

Tretter V, Kerschner B, Milenkovic I, Ramsden SL, Ramerstorfer J, Saiepour L, Maric HM, Moss SJ, Schindelin H, Harvey RJ, Sieghart W, Harvey K. 2011. Molecular basis of the gammaaminobutyric acid A receptor alpha3 subunit interaction with the clustering protein gephyrin. J Biol Chem 286(43):37702-37711.

Tretter V, Mukherjee J, Maric HM, Schindelin H, Sieghart W, Moss SJ. 2012. Gephyrin, the enigmatic organizer at GABAergic synapses. Front Cell Neurosci 6:23.

Triller A, Cluzeaud F, Pfeiffer F, Betz H, Korn H. 1985. Distribution of glycine receptors at central synapses: an immunoelectron microscopy study. J Cell Biol 101(2):683-688.

Triller A, Seitanidou T, Franksson O, Korn H. 1990. Size and shape of glycine receptor clusters in a central neuron exhibit a somato-dendritic gradient. New Biol 2(7):637-641.

Tyagarajan SK, Fritschy JM. 2014. Gephyrin: a master regulator of neuronal function? Nat Rev Neurosci 15(3):141-156.

Tyagarajan SK, Ghosh H, Yevenes GE, Imanishi SY, Zeilhofer HU, Gerrits B, Fritschy JM. 2013. Extracellular signal-regulated kinase and glycogen synthase kinase 3 beta regulate gephyrin postsynaptic aggregation and GABAergic synaptic function in a calpain-dependent mechanism. J Biol Chem 288(14):9634-9647.

Tyagarajan SK, Ghosh H, Yevenes GE, Nikonenko I, Ebeling C, Schwerdel C, Sidler C, Zeilhofer HU, Gerrits B, Muller D, Fritschy JM. 2011. Regulation of GABAergic synapse formation and plasticity by GSK3beta-dependent phosphorylation of gephyrin. Proc Natl Acad Sci U S A 108(1):379-384.

Van Keulen L. 1981. Autogenetic recurrent inhibition of individual spinal motoneurones of the cat. Neurosci Lett 21(3):297-300.

van Zundert B, Alvarez FJ, Tapia JC, Yeh HH, Diaz E, Aguayo LG. 2004. Developmental-dependent action of microtubule depolymerization on the function and structure of synaptic glycine receptor clusters in spinal neurons. J Neurophysiol 91(2):1036-1049. 
van Zundert B, Alvarez FJ, Yevenes GE, Carcamo JG, Vera JC, Aguayo LG. 2002. Glycine receptors involved in synaptic transmission are selectively regulated by the cytoskeleton in mouse spinal neurons. J Neurophysiol 87(1):640-644.

Vlachos A, Reddy-Alla S, Papadopoulos T, Deller T, Betz H. 2013. Homeostatic regulation of gephyrin scaffolds and synaptic strength at mature hippocampal GABAergic postsynapses. Cereb Cortex 23(11):2700-2711.

Wang H, Brozoski TJ, Caspary DM. 2011. Inhibitory neurotransmission in animal models of tinnitus: maladaptive plasticity. Hear Res 279(1-2):111-117.

Wojcik SM, Katsurabayashi S, Guillemin I, Friauf E, Rosenmund C, Brose N, Rhee JS. 2006. A shared vesicular carrier allows synaptic corelease of GABA and glycine. Neuron 50(4):575-587.

Wuchter J, Beuter S, Treindl F, Herrmann T, Zeck G, Templin MF, Volkmer H. 2012. A comprehensive small interfering RNA screen identifies signaling pathways required for gephyrin clustering. J Neurosci 32(42):14821-14834.

Yamanaka I, Miki M, Asakawa K, Kawakami K, Oda Y, Hirata H. 2013. Glycinergic transmission and postsynaptic activation of CaMKII are required for glycine receptor clustering in vivo. Genes Cells 18(3):211-224.

Zacchi P, Antonelli R, Cherubini E. 2014. Gephyrin phosphorylation in the functional organization and plasticity of GABAergic synapses. Front Cell Neurosci 8:103.

Zhang Y, Dixon CL, Keramidas A, Lynch JW. 2015. Functional reconstitution of glycinergic synapses incorporating defined glycine receptor subunit combinations. Neuropharmacology 89:391-397.

Zita MM, Marchionni I, Bottos E, Righi M, Del Sal G, Cherubini E, Zacchi P. 2007. Post-phosphorylation prolyl isomerisation of gephyrin represents a mechanism to modulate glycine receptors function. EMBO J 26(7):1761-1771. 


\section{Figure legends}

Figure 1. Basic organization of a glycinergic synapapse. Glycine accumulated in the axopalms through the activity of the GlyT2 glycine transporter and form this cytosolic pools is accumaulated inside vesicle by the vesicular inhibitory aminoacid transporter (VIAAT). Release glycine postsynaptic glycine receptor (GlyR) than when open they pass mainly chloride (Cl-) according to it electrochemical gradient (inmature neurons = hyperpolarizing; out-immature neurons = depolarizing). Postsynaptic GlyRs in mature neurons are mostly $\alpha 1 \beta$ subunit composition and are anchored postsynaptically by gephyrin to the submembrane actin cystoskeleton.

Figure 2. Different organizations of glycinergic synapses in the spinal cord. A, Gephyrin immunoreactivity reveals two different types of inhibitory synapse architecture based on gephyrin immunolabeling. Images are two dimensional projections of confocal stacks reconstructing gephyrin-IR clusters on the surface of a motoneuron (left) and a Renshaw cell (right). Insets show at higher magnification the gephyrin clusters and the dotted yellow line indicates the approximate apposition area of the inhibitory somatic bouton on top. Gephyrin clusters on the motoneuron surface are organized in rosettes and on Renshaw cells they form large patches with doughnut holes or pleomorphic morphologies. B, "Cheetah"-like small gephyrin rosette organizations in ventral interneurons and motoneurons correlate with mIPSCs of lower peak amplitude and faster time courses. "Jaguar"-like large gephyrin patches on Renshaw cells correlate with mIPSCs of higher peak amplitude and slower time course because the frequent incorporation of GABAergic components (they have dual decays with fast (f) and slow (s) components corresponding to GlyRs and $\mathrm{GABA}_{A}$ receptors). Quantal synaptic currents mIPSCs isolated in tetrodotoxin and with glutamate receptor blockers recorded in whole-cell using $\mathrm{CsCl}$ based recording solutions in patch pipettes $\left(\mathrm{E}_{\mathrm{Cl}}=0 \mathrm{mV}\right)$. The predominant mIPSCs in non-Renshaw cells (left, recordings from a ventral spinal cord interneuron) are of short duration and of relatively small peak amplitudes and most are blocked by GlyR antagonists. mIPSCs in Renshaw cells (right) are of larger amplitude and display more complex time courses. Their pharmacology frequently shows fast GlyR and slow $\mathrm{GABA}_{\mathrm{A}}$ receptor components. Gray traces are averages and peak scaled tracings of "mature" (P9 to P15) mIPSCs sampled from non-Renshaw and Renshaw ventral interneurons. Left shows the time course of GlyR only mIPSCs in non-Renshaw cells, right shows "mixed" GlyR and GABA ${ }_{A}$ receptors mIPSCS recorded from Renshaw cells. C, Electron microscopy reveals gephyrin immunoreactivity (diaminobenzidine electron dense precipitates) in several small postsynaptic densities occupying a small percentage of the apposition zone of inhibitory synaptic boutons over the motoneuron surface (left panel, bouton highlighted in blue). In contrast, inhibitory synaptic boutons on Renshaw cells (highlighted blue in right panel) are opposite to gephyrin-immunoreactive postsynaptic densities that occupy almost all the apposition area between bouton and postsynaptic membrane.

Figure 3. Schematic of principal gephyrin functions in the postsynaptic membrane and their regulation by mechanisms directly or indirectly related to synaptic and/or firing activity via depolarization. See text for explanations.

Figure 4. Gephyrin structural properties that define postsynaptic receptor clustering. A, The gephyrin gene contains 30 exons. Some can be alternatively spliced (gray boxes) giving rise to a variety of gephyrin isoforms. C-nomenclature corresponds to original definitions while in bold and italics are new terminology that includes positional information within the different domains of gephyrin (G,C or E) (after Fritschy et al., 2008 and Paarmann et al., 2006). Some cassettes are constitutively spliced (C2 and 
C6' in blue) and therefore present in all gephyrin isoforms. Others, are alternatively spliced and alter gephyrin oligomerization and receptor binding. Reportedly, the $\mathrm{C5}^{\prime}(\mathrm{G} 2)$ cassette affects gephyrin trimerization (see below) and can exclude GlyRs from the postsynaptic region (Meier and Grantyn, 2004; Bedet et al., 2006); the C4 cassette results in high density gephyrin oligomers and high GlyR binding (Herweg and Schwarz, 2012); the C3 cassette reduces gephyrin oligomerization and lowers GlyR binding (Herweg and Schwarz, 2012). B, Primary structure of gephyrin based on the widely used p1 clone that includes the $\mathrm{C} 2$ and $\mathrm{C} 6$ cassettes. Gephyrin has three domains: a G-domain, an E-domain and a C-linker region. G- and E-domains are respectively homologous to bacterial molybdenum cofactor (Moco) synthesizing enzymes MogA and MoeA (Stallmeyer et al., 1999). The E-domain contains the postsynaptic receptors and colylbistin binding regions, as indicated. All three domains contain phosphorylation sites (after Zachi et al., 2014) that alter their function; most concentrate in the C-linker. The C-linker also includes the alternatively spliced cassettes $\mathrm{C} 3$ and the C4 cluster. C, G-domains trimerize with high affinity although this is alter in $\mathrm{G} 2\left(\mathrm{C5}^{\prime}\right)$ gephyrin variants that form predominantly dimers. Nevertheless most gephyrin isoforms are believe to exist as trimers. Gephyrin trimers are flexible due to conformation variations in C-linker structure consequence of incorporation of different alternatively spliced cassettes, phosphorylation and different binding proteins. The E-domain dimerizes with low affinity but this increases after GlyR binding. Given the sensitivity of the C-linker region to protein degradation the exact tertiary structure of gephyrin is not fully known. In C, we depict different hypothetical spatial orientations between $\mathrm{E}$ and $\mathrm{G}$ domains to illustrate how they would generate hexagonal lattices of different gephyrin densities, as shown in D. D, Two theoretical hexagonal lattices derived from the two gephyrin conformations shown in C. A planar hexagonal lattice has been proposed as the preferential form of postsynaptic gephyrin oligomerization (Sola et al., 2004), although other conformations in nonamers and dodecamers have also been suggested (Herweg and Schwarz, 2012). Hexagonal lattices can form with different packing densities of gephyrin. Glycine receptors (GlyRs indicated by arrows, not to scale) bind to the E-domain and stabilize the gephyrin oligomer by, among other interactions, increasing the strength of E-domain dimers. Different forms of gephyrin hexagonal oligomerization result in different densities of GlyR binding sites. E, Gephyrin postsynatic accumulations therefore can occur at different densities and with more or less organization. F, Different patterns of gephyrin oligomerization give rise to differences in postsynaptic receptor clustering densities and accumulation ratios of $\mathrm{GABA}_{A}$ receptors to GlyRs. These are just three speculative examples. It is quite possible that postsynaptic receptor densities and $\mathrm{GABA}_{A} / \mathrm{GlyR}$ ratios are independently regulated. For example, Renshaw cells have high densities of GlyRs and high content of $G_{A B A}$ receptors (Geiman et al., 2002). See text for further information on the functionality of different gephyrin protein domains. 



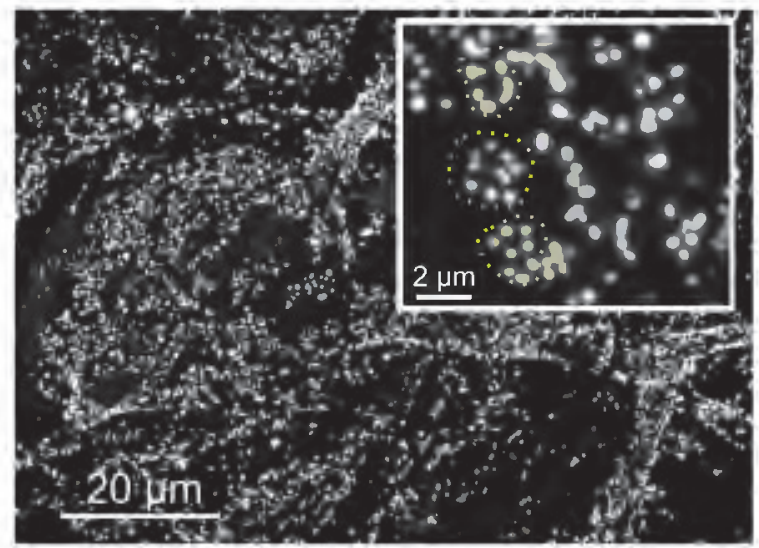

B

C

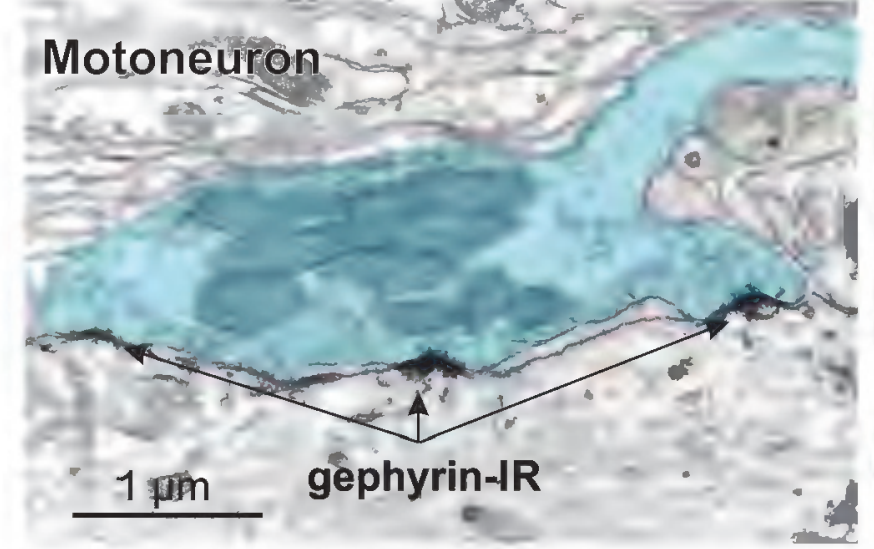

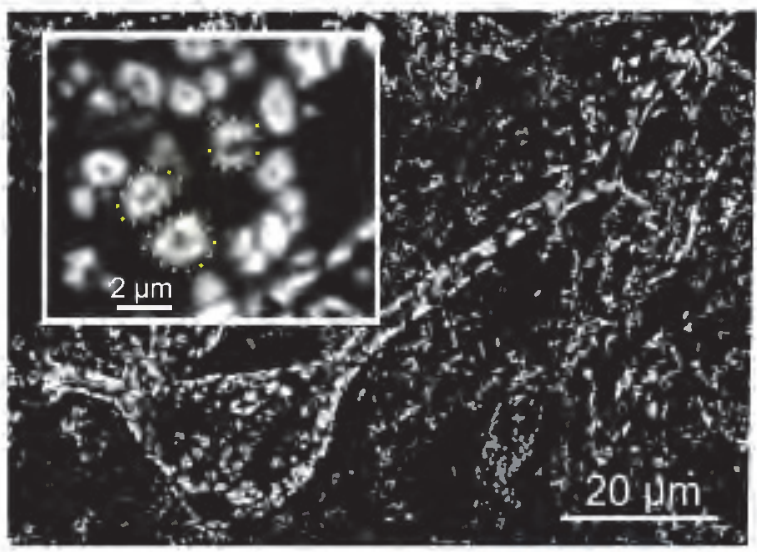

\section{Renshaw cell mIPSCs}

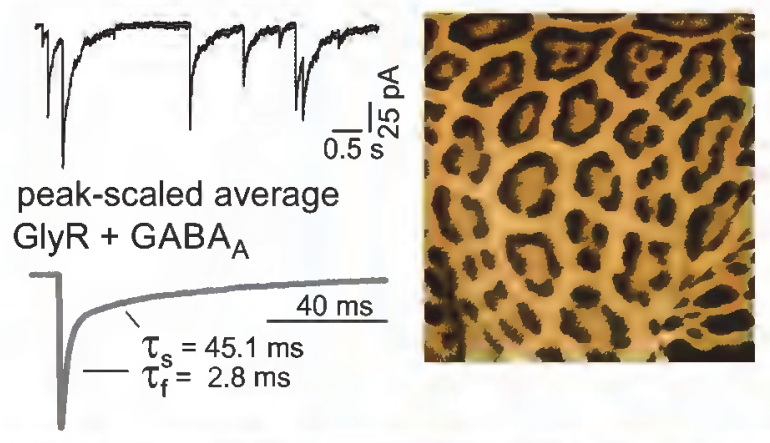

\section{Renshaw cell}

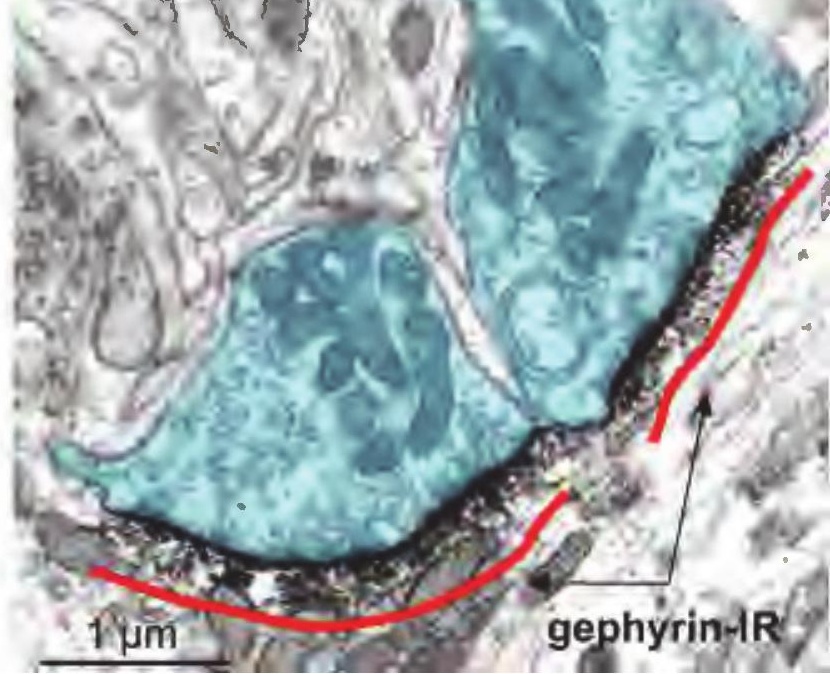


 \\ Neurexins}

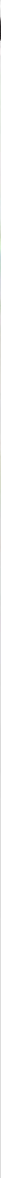




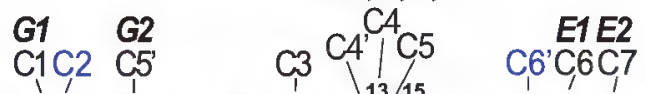

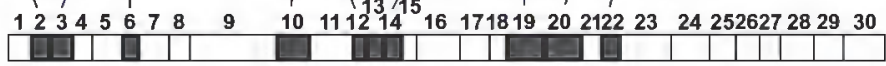

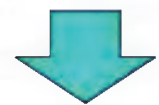

B Structure of gephyrin protein p1 clone (C2,C6 cassettes)

C Flexible gephyrin trimer

Binding sites

181aa collybistin GlyR 318aa

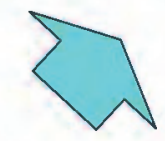

E-domains phosphorylation

splice variants protein interactions

$\mathrm{H}_{2} \mathrm{~N}$.

Thr96

Thr123

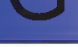

4

Thr198

Thr199 Ser270

Ser222

E|Ser188

Ser226

Thr 276
Ser 277
Ser280
Ser283
Thr281
Thr 286

\section{$=$

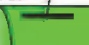

$\mathrm{GABA}_{A} \mathrm{Rc}$ 736aа
D Theoretical models of $+\mathrm{COOH}$

hexagonal lattices

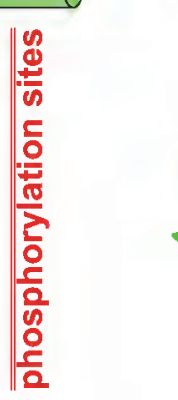

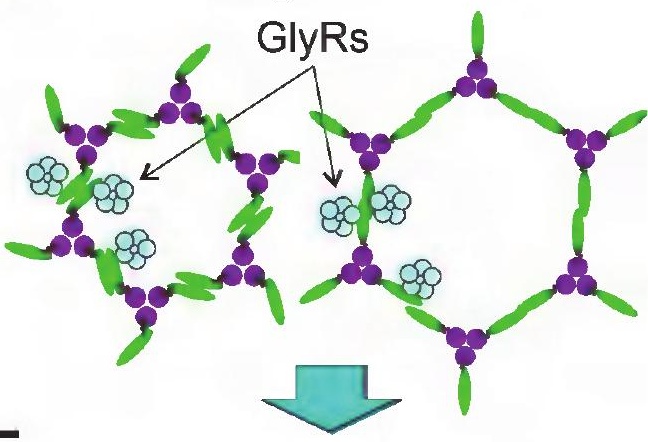

E Theoretical postsynaptic gephyrin oligomerizations

\section{GlyR/GABA $A_{A}$ receptor ratios}
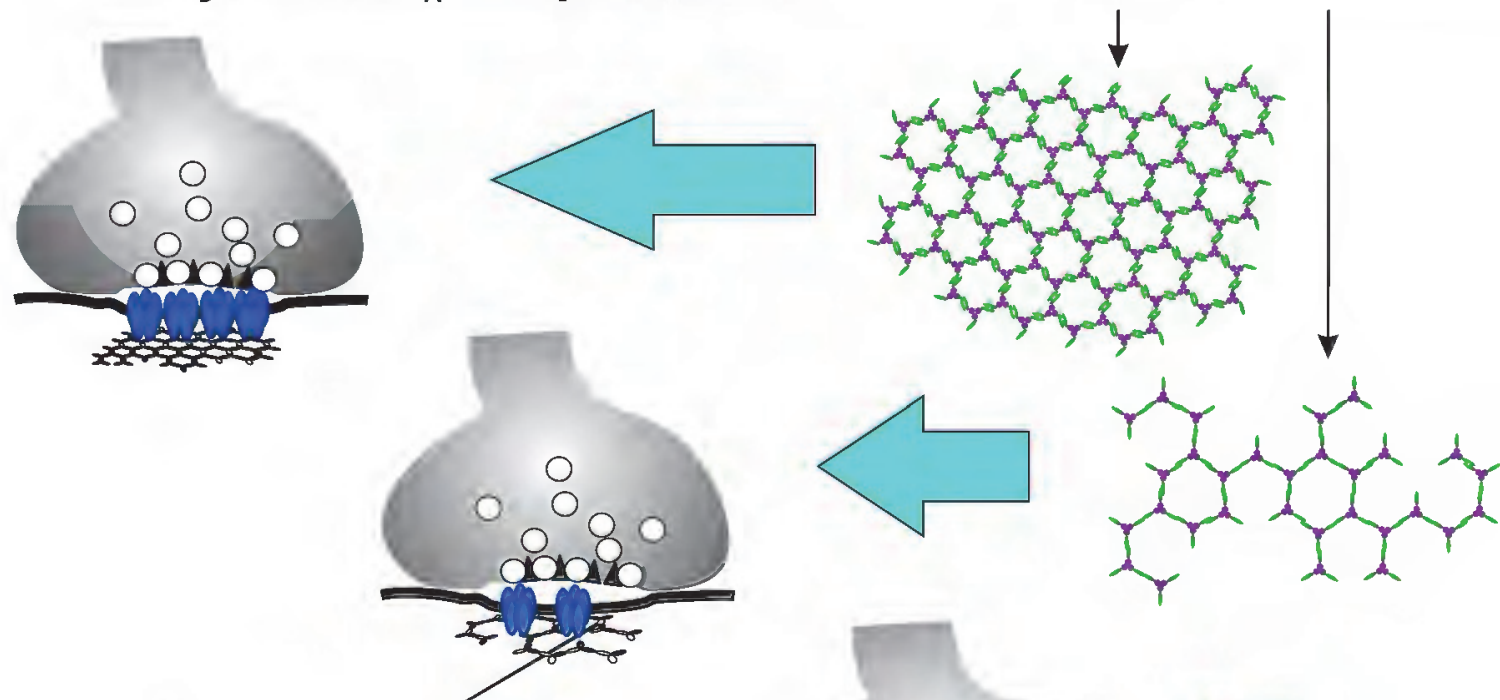

Glyeine receptors $\mathrm{GABA}_{A}$ receptors
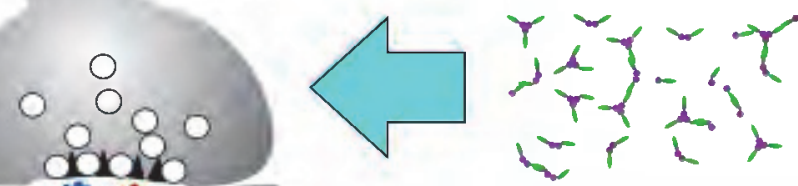